\title{
Medusa-Aqua system: simultaneous measurement and evaluation of novel potential halogenated transient tracers HCFCs, HFCs, and PFCs in the ocean
}

\author{
Pingyang $\mathbf{L i}^{1,2,3}$ and Toste Tanhua ${ }^{3}$ \\ ${ }^{1}$ State Key Laboratory of Organic Geochemistry and Guangdong-Hong Kong-Macao Joint Laboratory for Environmental \\ Pollution and Control, Guangzhou Institute of Geochemistry, Chinese Academy of Sciences, Guangzhou 510640, China \\ ${ }^{2}$ CAS Center for Excellence in Deep Earth Science, Guangzhou 510640, China \\ ${ }^{3}$ Marine Biogeochemistry, GEOMAR Helmholtz Centre for Ocean Research Kiel, 24105 Kiel, Germany
}

Correspondence: Toste Tanhua (ttanhua@geomar.de)

Received: 13 September 2019 - Discussion started: 11 October 2019

Revised: 30 January 2021 - Accepted: 9 February 2021 - Published: 9 April 2021

\begin{abstract}
This study evaluates the potential usefulness of the halogenated compounds HCFC-22, HCFC-141b, HCFC142b, HFC-134a, HFC-125, HFC-23, PFC-14, and PFC-116 as oceanographic transient tracers to better constrain ocean ventilation processes. We do this mainly in terms of four aspects of the characteristics of the potential tracers: input function (including atmospheric history and historical surface saturation), seawater solubility, feasibility of measurement, and stability in seawater; of these, atmospheric history and seawater solubility have been investigated in previous work. For the latter two aspects, we collected seawater samples and modified an established analytical technique for the Medusa-Aqua system to simultaneously measure these compounds. HCFC-22, HCFC-141b, HCFC-142b, HFC-134a, and HFC-125 have been measured in depth profiles in the Mediterranean Sea for the first time and for reproducibility in the Baltic Sea. We found that the historical surface saturation of halogenated transient tracers in the Mediterranean Sea is estimated to have been nearly constant at $94 \%$ based on historical data. Of the investigated compounds, HCFC-142b, HCFC-141b, and HFC-134a are found to currently be the most promising transient tracers in the ocean. The compounds that have the greatest potential as future tracers are PFC-14 and PFC-116, mainly hampered by the low solubility in seawater that creates challenging analytical conditions, i.e., low concentrations. HCFC-22 is found to be likely unstable in warm seawater, which compromises the potential as an oceanic transient tracer, although it is possibly useful in colder water. For the compounds HFC-125 and
\end{abstract}

HFC-23, we were not able to fully evaluate their potential as tracers due to inconclusive results, especially regarding their solubility and stability in seawater, but also with regard to potential analytical challenges. On the other hand, HFC-125, HFC-23, and HCFC-22 might not need to be considered because there are alternative tracers with similar input histories that are better suited as transient tracers.

\section{Introduction}

Ocean ventilation is defined as the process that transports perturbations such as the concentration of trace gases from the surface mixed layer into the ocean interior. Ocean ventilation and mixing processes play significant roles in climate. They largely control the accumulated uptake of anthropogenic carbon $\left(\mathrm{C}_{\mathrm{ant}}\right)$ at middle and high latitudes as well as the deep ocean's oxygen supply. One possible method to quantitatively describe these processes is based on transient tracer measurements.

\subsection{Why do we look for new transient tracers?}

Transient tracers include chronological transient tracers such as dichlorodifluoromethane (CFC-12), trichlorofluoromethane (CFC-11), and sulfur hexafluoride $\left(\mathrm{SF}_{6}\right)$, as well as radioactive transient tracers such as tritium-helium $\left({ }^{3} \mathrm{H}\right.$ $\left.{ }^{3} \mathrm{He}\right)$, argon-39 $\left({ }^{39} \mathrm{Ar}\right)$, and carbon-14 $\left({ }^{14} \mathrm{C}\right)$, although ${ }^{39} \mathrm{Ar}$ is assumed to be in steady state and cannot be regarded as 
a transient racer in the true meaning of the word. They have been used as oceanic transient tracers to study oceanic processes such as ventilation, mixing, and circulation. CFC-12 and CFC-11 have been used since the 1980s, whereas $\mathrm{SF}_{6}$ has only been used since the late 1990s. These compounds are stable in seawater under most circumstances; their seawater solubility functions are well-established (Warner and Weiss, 1985; Bullister et al., 2002), and their historical atmospheric concentrations over time are known (Walker et al., 2000; Bullister, 2015). However, the industrial uses of CFC-12 and CFC-11 were phased out as a result of the implementation of the 1987 Montreal Protocol on Substances that Deplete the Ozone Layer designed to curtail the degradation of the Earth's ozone layer. Therefore, the atmospheric concentrations of CFC-12 and CFC-11 have decreased since the early 2000s and the early 1990s, respectively (Bullister, 2015), which has reduced their usefulness as oceanographic transient tracers for recently ventilated water masses. Consequently, $\mathrm{SF}_{6}$ has been added to the suite of commonly measured oceanic transient tracers (Tanhua et al., 2004; Bullister et al., 2006) as it is an inert gas whose atmospheric abundance is increasing. Due to its very high global warming potential, some local restrictions on the production and use of $\mathrm{SF}_{6}$ have been imposed since 2006. However, the concentrations of $\mathrm{SF}_{6}$ in the atmosphere are still increasing, partly due to its long atmospheric lifetime. CFC-12, $\mathrm{SF}_{6}$, and CFC-11 can readily be measured on board research vessels at a reasonable rate from one seawater sample. 1,1,2-Trichloro-1,2,2-trifluoroethane (CFC-113) and carbon tetrachloride $\left(\mathrm{CCl}_{4}\right)$ have previously been used as oceanic transient tracers, but they have now been largely discarded since they have been found to be degraded in warm waters (Roether et al., 2001) and in low-oxygen waters (Wallace and Krysell, 1989; Huhn et al., 2001). The radioactive isotope ${ }^{39} \mathrm{Ar}$ is in many ways an ideal tracer for ocean circulation for older water masses, but its use has been impeded by difficult analytics. However, recent technological advancements have increased the feasibility of oceanic ${ }^{39} \mathrm{Ar}$ observations (Lu et al., 2014; Ebser et al., 2018). With the constraints of the weak signal of ${ }^{3} \mathrm{H}$ and the decreasing atmospheric mole fraction of CFC-12, presently only $\mathrm{SF}_{6}$ is a relatively reliable transient tracer on a seawater timescale of less than 100 years (Fig. 1). Since a combination of multiple transient tracers is needed to constrain ocean ventilation (Stöven and Tanhua, 2014; Holzer et al., 2018), it is useful to explore novel transient tracers with monotonically changing input functions for a better understanding of ventilation and mixing processes in the ocean.

\subsection{Potential alternative transient tracers}

There are a few general requirements for a transient tracer: (1) well-quantified sources and sinks, (2) no (or well-known) natural background, (3) large dynamic range, (4) feasible measurement techniques, and (5) non-reactivity and stabil- ity in seawater. In a previous work (Li et al., 2019), we focused on points (1), (2), and (3) for these potential alternative oceanographic transient tracers: hydrochlorofluorocarbons (HCFCs) such as HCFC-22, HCFC-141b, and HCFC142b; hydrofluorocarbons (HFCs) such as HFC-134a, HFC125, and HFC-23; and perfluorocarbons (PFCs) such as PFC$14\left(\mathrm{CF}_{4}\right)$ and PFC-116. The atmospheric abundances of most HCFCs, HFCs, and PFCs are increasing. Here we call the potential chronological transient tracers HCFC-22, HCFC141b, HCFC-142b, HFC-134a, HFC-125, HFC-23, PFC-14, and PFC-116 the "Medusa tracers" after the analytical instrument used to measure them. Fortunately, the different atmospheric histories of the potential alternative transient tracers (Li et al., 2019) allow us to explore one or several compounds to replace or supplement the established transient tracers (Fig. 1).

\subsection{Stability of alternative tracers in seawater}

Chemical reactions (including hydrolysis), adsorption to particles, and biological degradation processes should be considered with regard to the stability of compounds in seawater. There are few studies of the stability of the Medusa tracers and close to none on their stability in seawater. Indications of stability include chemical structure and atmospheric lifetime. For instance, PFCs have very long atmospheric lifetimes, i.e., $>50000$ and $>10000$ years for PFC-14 and PFC-116, respectively. PFC-14 $\left(\mathrm{CF}_{4}\right)$ is stable at temperatures of at least $1200^{\circ} \mathrm{C}$, and the rate of hydrolysis of $\mathrm{CF}_{4}$ is immeasurably small (Ravishankara et al., 1993; Cicerone, 1979). In addition, there are no indications of biological processes that can break C-F bonds, indicating that PFCs are likely to be very stable in the environment.

The contribution of the partial atmospheric lifetime with respect to oceanic uptake of selected HCFCs and HFCs to the total lifetimes is another indirect indication of the stability in seawater. Such partial atmospheric lifetimes depend on solubility in seawater and other losses relative to atmospheric concentration, and they are always larger than total lifetimes. Considering the low fraction of these mainly non-polar compounds in the ocean, a small loss in the ocean is insignificant for the overall budget of the compound but can still be indicative of the potential as a transient tracer. As suggested from previous studies (Yvon-Lewis and Butler, 2002; Carpenter et al., 2014) using this method, HCFCs and HFCs seem to be stable in seawater, although with large uncertainties (Sect. S1 and Table S1 in the Supplement). Note that the partial atmospheric lifetimes with respect to oceanic uptake in Table S1 were calculated only considering the chemical degradation process.

Another route is to compare surface saturations of a tracer with unknown stability to those of a compound that is known to be stable in seawater, e.g., CFC-12. The average surface saturation of HCFCs tends to be higher than those of CFC-12 


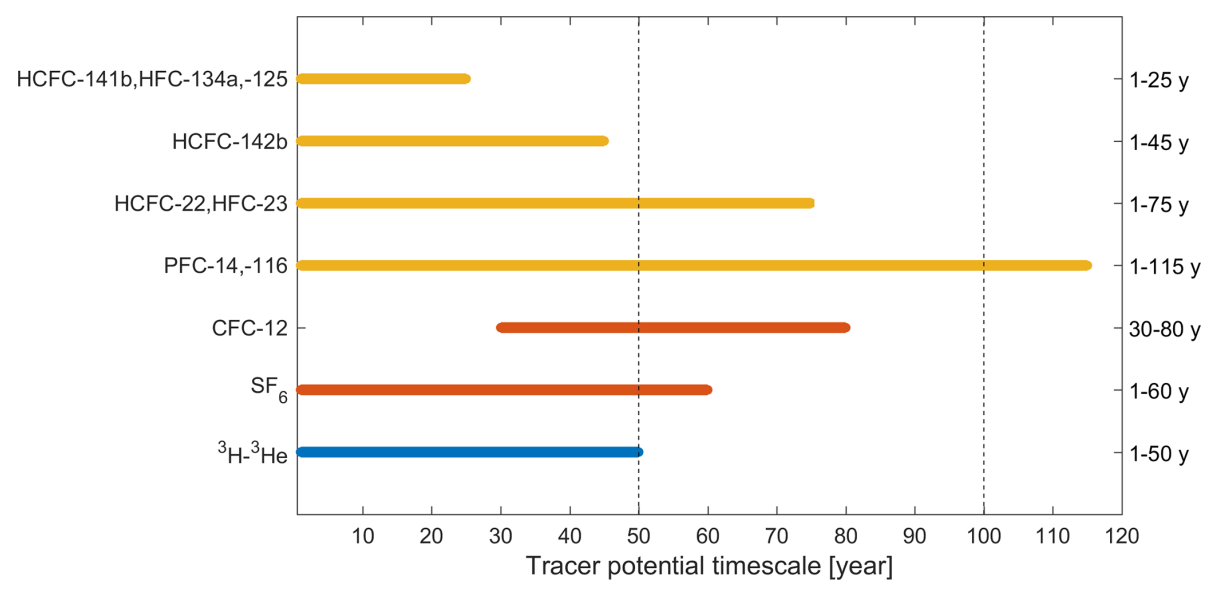

Figure 1. Seawater timescales ("tracer age ranges") of potential chronological transient tracers (selected HCFCs, HFCs, and PFCs; yellow) and traditional chronological transient tracers (CFC-12 and $\mathrm{SF}_{6}$; red) combined with radioisotope dating using radioactive transient tracers $\left({ }^{3} \mathrm{H}^{3}{ }^{3} \mathrm{He}\right.$; blue). Tracer age ranges of chronological transient tracers are approximately estimated from Fig. 6 (see below), while those of radioactive transient tracers are from Aggarwal (2013).

(Table S2). This may suggest that HCFCs are stable enough to be suitable as tracers in the ocean.

Based on these discussions, PFCs are stable, while HCFCs and HFCs are potentially stable in the ocean when only considering the chemical degradation process and surface saturation in seawater (only for HCFCs). However, the influences of oxygen dependence and biological degradation processes in seawater have not been investigated (Yvon-Lewis and Butler, 2002). For a compilation of published information on biodegradation in freshwater and soil, see Sect. S2 and Table S3. In summary, not enough information is known on the stability of the selected HCFCs and HFCs in the ocean.

\subsection{Goals of this study}

This study extends the work by $\mathrm{Li}$ et al. (2019), with a focus on evaluating if rapid, relatively inexpensive, and accurate measurements are possible and if these compounds are conservative in the oceanic environment. We also estimate the historical surface saturation to supplement the input function and discuss differences in tracer input functions and their ability to provide additional information on ventilation. A suite of observations of transient tracers with sufficiently different input functions would support the empiric determination of transit time distributions (TTDs), as reported in Stöven and Tanhua (2014). As the first step towards this, these Medusa tracers have been measured, sometimes for the first time, and the results were interpreted to identify their possible application as transient tracers in the ocean. The Mediterranean Sea was chosen for this study because of its rapid ventilation, which causes transient tracers to penetrate most of the water column. In addition, we report from sampling at a shallow station in the southwestern Baltic Sea.

\section{Measurement system}

\subsection{Measurement of HCFCs, HFCs, and PFCs}

Measurement of halogenated compounds is often performed by gas-solvent extraction techniques, e.g., purge-and-trap whereby an inert gas is bubbled through a seawater sample to move the analytes from the sample into a cold trap for preconcentration. By desorbing the content of the trap, the sample can then be injected into a gas chromatograph (GC) for separation and detection. This is a well-established technique that has been used successfully for CFCs and $\mathrm{SF}_{6}$ (Bullister and Weiss, 1988; Bullister and Wisegarver, 2008), ideally achieving accuracies of the order of $1 \%$ (Bullister and Tanhua, 2010). However, several HCFCs and HFCs (i.e., HCFC22, HFC-134a, and HFC-125) have low responses and large uncertainties when they are measured by an electron capture detector (ECD) that is normally used for CFC-12 and $\mathrm{SF}_{6}$ (Lobert et al., 1995; Sousa and Bialkowski, 2001; Beyer et al., 2014). One alternative is to use a mass spectrometer (MS) for detection, which has the advantage of scanning for unique masses for different compounds, allowing for simultaneous identification and quantification. HCFCs and HFC134a measurements by GC-MS in seawater samples have been reported in previous studies (Lobert et al., 1996; Ooki and Yokouchi, 2011).

\subsection{The Medusa-Aqua system}

The Medusa GC-MS system (shortened to the Medusa system) for the precise and simultaneous analysis of a wide range of volatile trace gases in the atmosphere has been developed at the Scripps Institution of Oceanography (Miller et al., 2008). This system includes two traps kept at accurately controlled temperatures to trap the volatile gases. The 
packing material of the traps and the temperature during the trapping stage are designed in a way that allows for the fractionation of the compounds on two traps. In this way, interferences from atmospheric permanent gases can be avoided and hard-to-measure gases like PFC-14 $\left(\mathrm{CF}_{4}\right)$ can be measured. This analytical system was designed to automatically and continuously measure air samples at Advanced Global Atmospheric Gases Experiment (AGAGE) remote field stations (Prinn et al., 2018) and is unique in that it provides high-accuracy measurements of more than 40 compounds, including halocarbons, hydrocarbons, and sulfur compounds involved in ozone depletion and/or climate forcing from the same sample. The measurement precisions of most halogenated compounds are less than $0.5 \%$ in $2 \mathrm{~L}$ ambient air. The Medusa-Aqua system, developed based on the Medusa system, is able to measure the majority of the 40 halogenated compounds in seawater samples.

The Medusa-Aqua system consists of a Medusa system (Miller et al., 2008) and a seawater sample pretreatment system (Fig. 2). The Medusa system consists of a cryogenic pre-concentration unit, an Agilent $6890 \mathrm{~N}$ gas chromatograph (GC), and an Agilent 5975B quadrupole mass spectrometer (MS). The seawater sample pretreatment system purges gaseous tracers from the water samples before injecting them into the Medusa system, replacing the air sampling device of the original Medusa system.

The main difference between the Medusa and MedusaAqua system is that the former uses an air-pump module as the gas sample pretreatment system and the sample volume is determined by an integrating mass flow controller (MFC), while the latter uses a purge module as the seawater sample pretreatment system and a gravimetrically calibrated standard loop for standard gas determination. For the injection of water samples to the system, we use the Ampoule Cracker system, as designed by Vollmer and Weiss (2002) and then modified by Stöven (2011).

\section{Sampling and measurement}

Here we describe the sampling and measurement methods for samples collected from cruise MSM72 to the Mediterranean Sea in March and cruise AL516 to the Baltic Sea in September 2018. Over the past years, we have collected samples on a few cruises and improved our method (Sect. S3, Figs. S1-S7, and Tables S4-S6).

\subsection{Sample collection}

Seawater samples were collected throughout the water column in three areas of the Mediterranean Sea (Fig. 3): southern Ionian Sea (SIS), Tyrrhenian Sea (TS), and western Mediterranean Sea (WMS) on cruise MSM72 by the research vessel Maria S. Merian from 2 March to 3 April 2018 along the GO-SHIP line MED-01 (Hainbucher et al., 2020).
One station $\left(10.1^{\circ} \mathrm{E}, 54.5^{\circ} \mathrm{N}\right)$ in the Baltic Sea was sampled on cruise AL516 by the research vessel Alkor from 12 to 22 September 2018 (Booge, 2018). These seawater samples were collected in glass ampoules $(\sim 1.3 \mathrm{~L})$ connected to Niskin bottles via a stainless-steel mounting system (Vollmer and Weiss, 2002). A total of $5 \mathrm{~min}$ is needed for the seawater to fill up a whole glass ampoule, and the sampling process lasted for $15 \mathrm{~min}$ to allow the seawater to flush the whole ampoule volume three times. The ampoules were flame-sealed immediately after sampling under a flow of high-purity $\mathrm{N}_{2}$ (Air Liquide, grade 6.0, Germany) and then sent back to the laboratory in Kiel for measurement. As seen in Fig. 3, no onboard CFC-12 and $\mathrm{SF}_{6}$ measurements (on a PT-GC-ECD) were conducted on the stations we sampled for the MedusaAqua system in the Mediterranean Sea, although they were measured at both adjacent stations located $15 \mathrm{~nm}$ away along the cruise track.

\subsection{Gas extraction, separation, and detection}

The flow scheme for the Medusa-Aqua system is shown in Fig. 2. Before measurement, each ampoule sample was immersed in a warm water bath at $65^{\circ} \mathrm{C}$ overnight to support the transfer of the gases into the headspace and to enhance the purging efficiency. The stem of the ampoule is inserted vertically into the cracking chamber and is held by a nut secured by a Teflon ferrule. Then the cracking chamber is flushed with $\mathrm{N}_{2}$ (grade 6.0) for $10 \mathrm{~min}$ to flush out ambient air completely. A blank test for the cracking chamber is made by simulating an extraction without breaking the glass ampoule. For analysis, the tip of the ampoule's stem is shattered inside the enclosed cracking chamber by rotating the cracking paddle. A straight purge tube is then inserted down into the ampoule until it touches the ampoule bottom for finer bubbles. These bubbles will help strip the dissolved gases out of the seawater and, more importantly, from the headspace.

The extraction process is started by purging the gases in the ampoule with $\mathrm{N}_{2}$ (grade 6.0) for $20 \mathrm{~min}$ at a flow rate of $100 \mathrm{~mL} \mathrm{~min}^{-1}$. Water vapor is removed from the sample by passing the gases through two Nafion dryers (N1 and N2) of $1.8 \mathrm{~m}$ length and one (N3) of $0.6 \mathrm{~m}$ length. The counterflow rate of Nafion dryer gas $\left(\mathrm{N}_{2}\right.$, grade 5.0) was set to $120 \mathrm{~mL} \mathrm{~min}^{-1}$. After the purge gas is injected into Medusa, the following path is the same as described by Miller et al. (2008). The tracer gases are separated on the main column with helium (Air Liquide, grade 6.0, Germany) as the carrier gas and subsequently detected by the MS. The mass of seawater in the ampoules was calculated as the difference between the full weight of the ampoule before measurement and the empty ampoule (including glass splinters) after rinsing with distilled water and drying in an oven. 


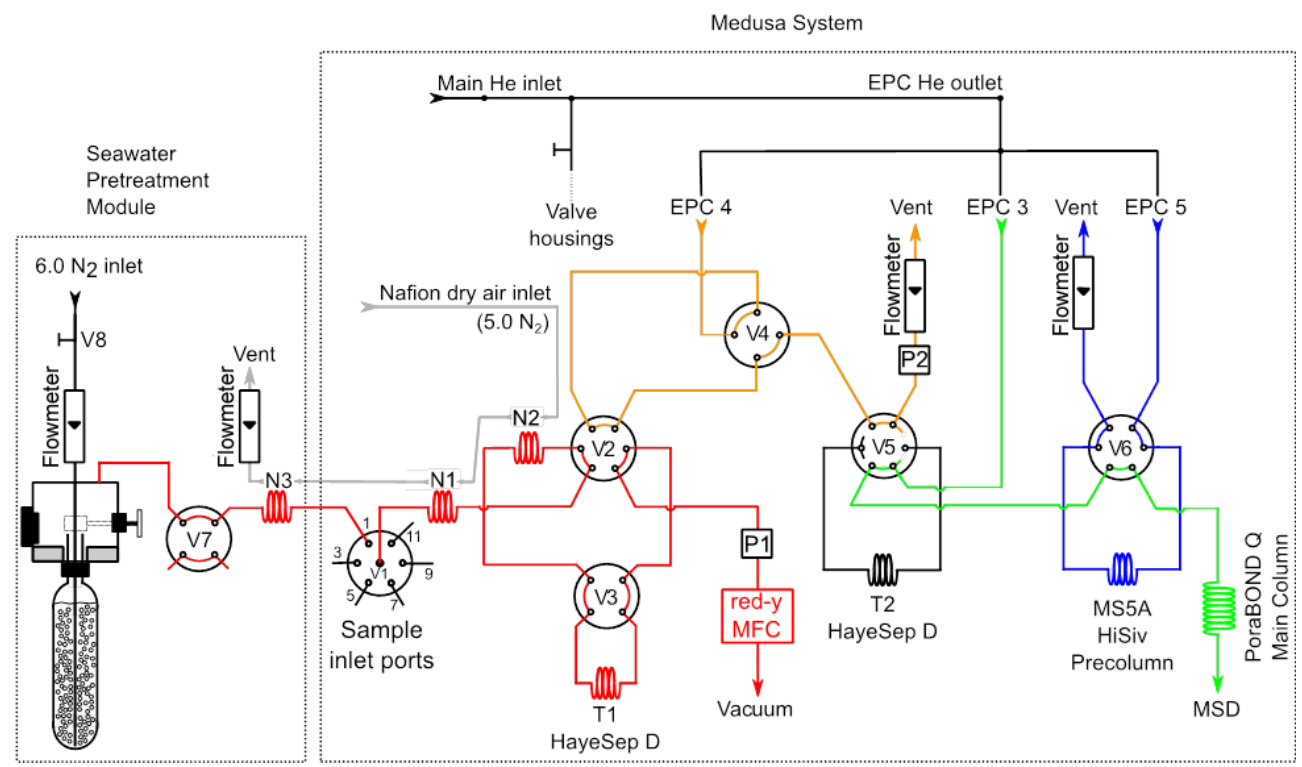

Figure 2. The Medusa-Aqua system flow scheme with the Medusa system identical to Miller et al. (2008). The seawater pretreatment module is added to degas gaseous tracers from samples before injection into Medusa. Electronic pressure controllers (EPC3, EPC4, and EPC5) supply helium throughout the system. The mass flow controller (MFC) is used to measure the sample volume downstream of Trap 1 (T1). The cryogenic packing materials are $200 \mathrm{mg}$ of 100/120 mesh HayeSep D (HSD) for Trap 1 (T1) and $5.5 \mathrm{mg}$ of HSD adsorbent for Trap 2 (T2). N1-N3 are the Nafion driers, and V1-V8 are multiport valves. P1 and P2 are pressure transducers (100PSI-A-DO, All Sensors Corporation, Morgan Hill, CA).

\subsection{Standard and calibration}

The standard gas is a tertiary standard calibrated by the Scripps Institution of Oceanography (SIO) on the AGAGE relative scale "SIO-R1". For details about the propagation of the standard, see Miller et al. (2008). Gravimetric calibration scales and calibrated errors of compounds in the tertiary standard are reported in Table 1. Measurements in seawater are reported on the latest SIO absolute calibration scales for HFC-125 (SIO-14), HFC-23 and PFC-14 (SIO-07), and other compounds (SIO-05). The tertiary calibration scale is directly used as a working standard to determine weekly calibration curves and daily drift corrections. These calibration measurements are made by multiple injections of the gas in a $10.0 \mathrm{~mL}$ gravimetrically calibrated sample loop. Each injection lasts $40 \mathrm{~s}$ at a flow rate of $50-60 \mathrm{~mL} \mathrm{~min}^{-1}$. The detector responses for compounds in Table 1 are linear in the range of our measurements.

\subsection{Purge efficiency, detection limit, and precision}

Each sample was measured three to six times until none of the compounds in Table 1 could be detected in the seawater sample so that the purge efficiency for all compounds is $100 \%$. The averaged stripping efficiencies for the first purge of seawater samples from cruise MSM72 are $92.5 \pm 5.4 \%$ for CFC-12, 76.6 $\pm 7.9 \%$ for HCFC-22, $87.5 \pm 8.3 \%$ for HCFC-141b, $83.2 \pm 10.6 \%$ for HCFC-142b, $83.1 \pm 7.5 \%$ for HFC-134a, and $88.9 \pm 7.5 \%$ for HFC-125. Their detec- tion limits are $29.8,13.8,4.0,3.2,7.3$, and $1.2 \mathrm{fmol} \mathrm{kg}^{-1}$, respectively (Table 1), based on the signals corresponding to the blank values plus 10 standard deviations.

The precision of the measurement is dependent on the size of the ampoules and the amount of tracer in the sample; the sample with a higher amount of tracer has better precisions than those with a lower amount. The precisions (or reproducibilities) for seawater sample measurements were determined by the relative standard deviations (RSDs) of the concentrations for duplicate samples from the Baltic Sea (Table 1). They are $0.4 \%, 3.1 \%, 6.1 \%, 1.8 \%, 9.7 \%$, and $2.0 \%$ for CFC-12, HCFC-22, HCFC-141b, HCFC-142b, HFC-134a, and HFC-125, respectively. To validate the reproducibility of the analytical setup, we took seawater from the tropical Atlantic Ocean and let it equilibrate with the atmosphere in the laboratory. The water was then sampled from Niskin bottles in the same way as during a cruise and flamesealed in ampoules, although for this experiment we used 300 $\mathrm{mL}$ samples. The reproducibilities for CFC-12, HCFC-22, HCFC-141b, and HCFC-142b measurements from four duplicate samples are $3.7 \%, 2.0 \%, 3.5 \%$, and $3.4 \%$, respectively (Table 1).

For the target compounds measured by the Medusa-Aqua system from the Mediterranean Sea and Baltic Sea, the concentrations of $\mathrm{SF}_{6}$, PFC-14, and PFC-116 in most seawater samples were lower than the detection limit, and HFC-23 had unstable and nonzero blank values in all measurements, preventing us from evaluating those results. The observations of 

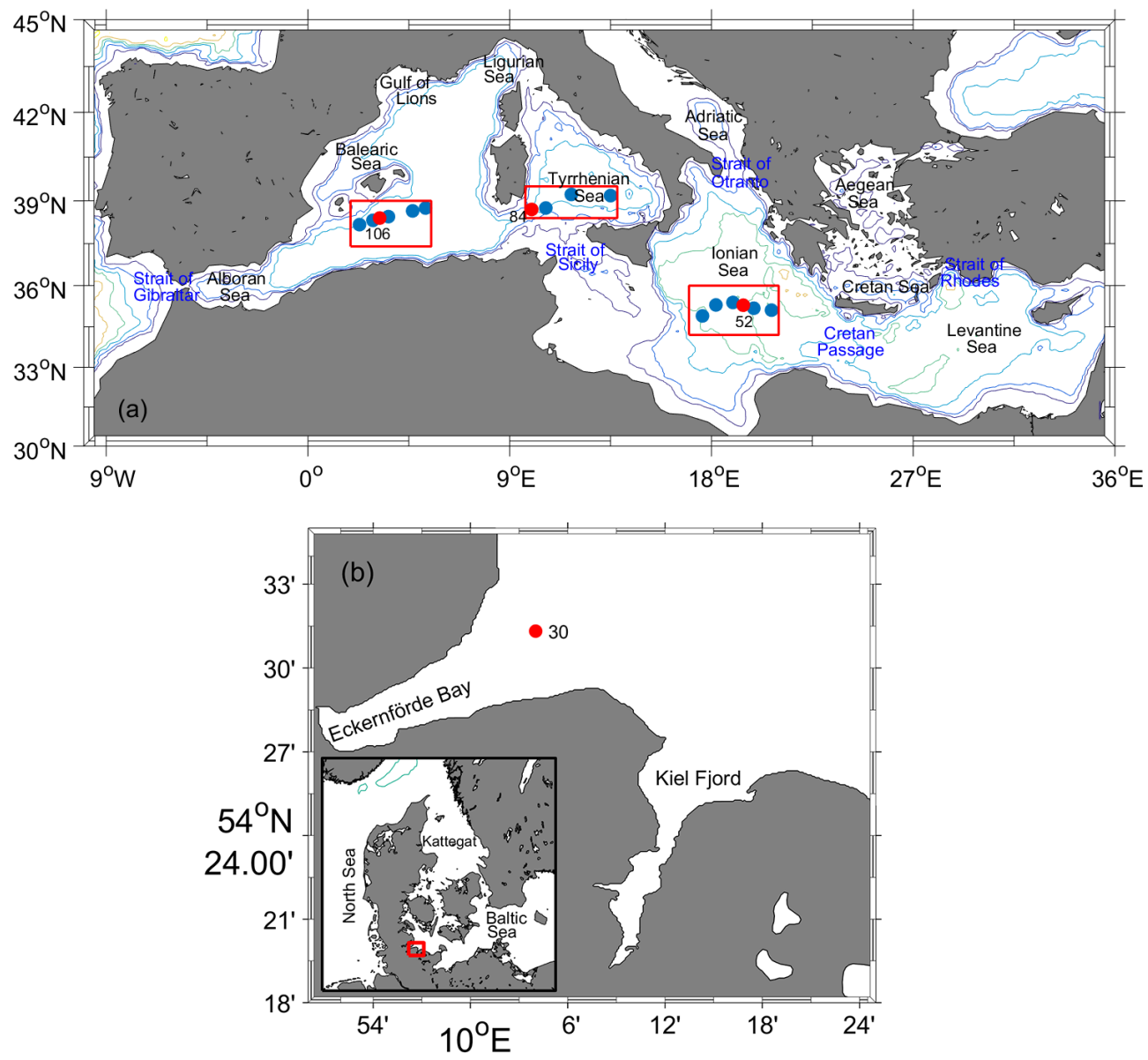

Figure 3. Locations of sampling sites from (a) cruise MSM72 in the Mediterranean Sea in three areas: southern Ionian Sea (SIS), Tyrrhenian Sea (TS), and western Mediterranean Sea (WMS), as well as (b) cruise AL516 in the Baltic Sea. Sampling sites marked with red solid circles indicate samples measured by the Medusa-Aqua system for HCFCs, HFCs, PFCs, and CFC-12; blue solid circles are for CFC-12 and SF 6 measured by the PT-GC-ECD. The depth contours are 500, 1000, 2000, 3000, 4000, and $5000 \mathrm{~m}$.

Table 1. Selected Medusa-Aqua analytes, calibration scales, and calibrated errors of the standard gas, detection limit, and seawater measurement precisions.

\begin{tabular}{|c|c|c|c|c|c|c|c|}
\hline $\begin{array}{l}\text { Industrial name } \\
\text { (abbreviation) }\end{array}$ & $\begin{array}{l}\text { Chemical } \\
\text { formula }\end{array}$ & Full name & $\begin{array}{l}\text { Calibration } \\
\text { scale }\end{array}$ & $\begin{array}{r}\text { Calibrated errors } \\
\text { of the standard } \\
\text { gas }(\%)\end{array}$ & $\begin{array}{l}\text { Detection limit } \\
\quad\left(\mathrm{fmol} \mathrm{kg}^{-1}\right)\end{array}$ & $\begin{array}{r}\text { Precision }^{\mathrm{a}} \\
(\%)\end{array}$ & $\begin{array}{r}\text { Precision }^{\mathrm{b}} \\
(\%)\end{array}$ \\
\hline $\mathrm{SF}_{6}$ & $\mathrm{SF}_{6}$ & sulfur hexafluoride & SIO-05 & 0.37 & 0.5 & - & - \\
\hline CFC-12 & $\mathrm{CCl}_{2} \mathrm{~F}_{2}$ & dichlorodifluoromethane & SIO-05 & 0.08 & 29.8 & 0.4 & 3.7 \\
\hline HCFC-22 & $\mathrm{CHClF}_{2}$ & chlorodifluoromethane & SIO-05 & 0.22 & 13.8 & 3.1 & 2.0 \\
\hline HCFC-141b & $\mathrm{CH}_{3} \mathrm{CCl}_{2} \mathrm{~F}$ & 1,1-dichloro-1-fluoroethane & SIO-05 & 0.20 & 4.0 & 6.1 & 3.5 \\
\hline HCFC-142b & $\mathrm{CH}_{3} \mathrm{CClF}_{2}$ & 1-chloro-1,1-difluoroethane & SIO-05 & 0.21 & 3.2 & 1.8 & 3.4 \\
\hline HFC-134a & $\mathrm{CH}_{2} \mathrm{FCF}_{3}$ & 1,1,1,2-tetrafluoroethane & SIO-05 & 0.21 & 7.3 & 9.7 & - \\
\hline HFC-125 & $\mathrm{CHF}_{2} \mathrm{CF}_{3}$ & pentafluoroethane & SIO-14 & 0.23 & 1.2 & 2.0 & - \\
\hline HFC-23 & $\mathrm{CHF}_{3}$ & fluoroform & SIO-07 & 0.49 & 6.7 & - & - \\
\hline PFC-14 & $\mathrm{CF}_{4}$ & carbon tetrafluoride & SIO-05 & 0.30 & 0.4 & - & - \\
\hline PFC-116 & $\mathrm{CF}_{3} \mathrm{CF}_{3}$ & hexafluoroethane & SIO-07 & 0.32 & 1.4 & - & - \\
\hline
\end{tabular}

${ }^{a}$ Precision (reproducibility, $1 \sigma$ ) of tracers in seawater was determined by $\sim 1.3 \mathrm{~L}$ samples at 23.5 dbar from cruise AL516 in the Baltic Sea in September 2018 . ${ }^{\mathrm{b}}$ Precision of tracers calculated from four replicate measurements of $300 \mathrm{~mL}$ seawater samples equilibrated with air in the laboratory. 
CFC-12, HCFC-22, HCFC-141b, HCFC-142b, HFC-134a, and HFC-125 (in pmol kg-1) measured by the Medusa-Aqua system in seawater from both cruises are shown in Table S7 with quality flags marked.

\subsection{Quality control}

In order to evaluate the precision and accuracy of seawater measurements by the Medusa-Aqua system, the observations of CFC-12 measured by the Medusa-Aqua system are compared with those in adjacent stations measured on board by the PT-GC-ECD system in the Mediterranean Sea (Fig. 4). We performed a two-step quality control procedure on the Medusa data whereby in the first step outliers were flagged as bad (flag 3 in Table S7); in a second step we flagged data as likely bad (flag 5) if the Medusa CFC-12 values were inconsistent with the CFC-12 values from PT-GC-ECD and as good (flag 2) when they were consistent (Fig. 4). "Inconsistent" means that the misfits of CFC-12 concentrations measured by the two instruments are more than 3 times the standard deviations $(3 \sigma)$, indicating a possible issue during the sampling process. The two-step quality control process led to nine samples in the Mediterranean Sea that meet all these criteria and have similar concentrations as the PT-GC-ECD observations. For such samples, the averaged difference of CFC-12 concentrations measured by the two different instruments is $5.9 \pm 4.6 \%$ at roughly the same depth by ignoring their distance differences.

\subsection{Comparison of instruments measuring CFC-12}

As mentioned in the previous section, CFC-12 was measured by both the Medusa-Aqua system and a purge-and-trap GCECD instrument (the syringe PT-GC-ECD system) used on board cruise MSM72. The latter is a mature system to measure CFC-12, $\mathrm{SF}_{6}$, and $\mathrm{SF}_{5} \mathrm{CF}_{3}$ (Stöven, 2011; Stöven and Tanhua, 2014; Stöven et al., 2016; Bullister and Wisegarver, 2008). For comparison, information on the performance of a similar purge-and-trap system setup (Cracker PT-GC-ECD) to measure flame-sealed ampoules for $\mathrm{CFC}-12$ and $\mathrm{SF}_{6}$ is added to a comparison of the three instrument setups (Table 2). Compared to other systems, the Medusa-Aqua system has a lower purge efficiency due to the larger sampling volumes if only considering a single purge (although we used multiple purge cycles to increase the purge efficiency and reduce the uncertainty). It also has lower precision than that of the syringe PT-GC-ECD (but higher than that of the Cracker PT-GC-ECD system) and can measure more compounds.

\section{Interpretation of transient tracer distributions}

\subsection{Time range}

The time range in which a tracer can be used as a transient tracer is defined by its input function. For chronological tran- sient tracers, the input functions are described by their atmospheric histories and historical surface saturations. For ideal applicability, atmospheric histories of tracers should increase monotonically in the atmosphere. For older waters and low tracer concentrations, the precision and detection limits will be limiting factors (Tanhua et al., 2008; Stöven et al., 2015). Figure 5 shows the atmospheric histories of HCFC-22, HCFC-141b, HCFC-142b, HFC-134a, HFC-125, HFC-23, PFC-14, PFC-116, CFC-12, and $\mathrm{SF}_{6}$ in the Northern Hemisphere (Bullister, 2015; Li et al., 2019).

\subsection{Tracer age and the transit time distribution (TTD)}

Tracer age (or partial pressure age) is defined as the age of a water parcel based on a purely advective flow in the ocean. Figure 6 shows the relation between the relative tracer concentrations in percent, i.e., normalized to the contemporaneous atmospheric concentrations, and the corresponding tracer ages for 10 transient tracers in two different sampling years (2018 and 2000), which highlights tracer similarities and the specific application range for each tracer.

Similar trends are found for the following tracer couples: HCFC-141b and HCFC-142b, HFC-134a and HFC-125, SF 6 and HCFC-22-HFC-23, and PFC-14 and PFC-116. Assuming that all these compounds fulfill the other criteria as transient tracers, it is enough to choose one of each couple for transient tracer work (i.e., also using the other compound in the pair adds little new information).

If the relative tracer concentrations are higher than $100 \%$ in Fig. 6, there has been a decrease in atmospheric concentrations, e.g., for CFC-12. When the atmospheric history of a compound is not monotonically changing, the equilibrium atmospheric mole fraction (and ultimately the age associated with that mole fraction) calculated from its concentration in the ocean is not unique, reducing its potential as a transient tracer ( $\mathrm{Li}$ et al., 2019). Thus, the tracer age range is a function of the sampling year. For instance, the useful tracer age range of CFC-12 is 30-80 and 1-60 years for sampling in 2018 and 2000, respectively (Fig. 6). This indicates that the ability of CFC-12 as a transient tracer for recently ventilated water is decreasing with time, but CFC-12 still provides important time information for intermediate and deep water layers with moderate ventilation timescales. It is worth pointing out that PFCs have a longer tracer age range compared to other compounds, even CFC-12, among the chronological transient tracers (Fig. 6).

We used a well-established ocean ventilation model, the transit time distribution (TTD) model based on the Green's function (Hall and Plumb, 1994), describing the propagation of tracer boundary conditions into the interior. This model is based on a one-dimensional flow model with a time-invariant advective velocity and diffusivity gradient, and it is thus known as the one-dimensional inverse Gaussian transit time distribution (IG-TTD). The key variables are the mean age $\Gamma$ and the width of the distribution $\Delta$ (Waugh et al., 2003). The 

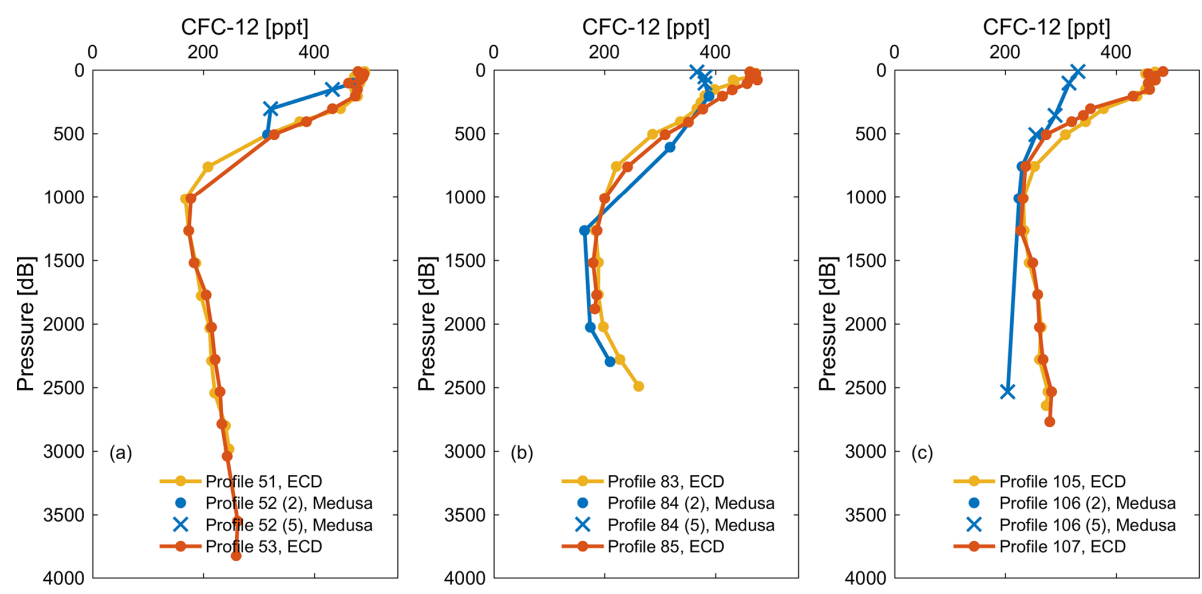

Figure 4. Comparison of CFC-12 observations from cruise MSM72 measured by the PT-GC-ECD (ECD) and the Medusa-Aqua system (Medusa) in three areas: (a) southern Ionian Sea, (b) Tyrrhenian Sea, and (c) western Mediterranean Sea. Samples flagged as good (flag 2) are shown as dots, whereas for samples that are deemed inconsistent with PT-GC-ECD samples are flagged as likely bad (here we used flag 5 ; see text). In the following plots, we show all data with a quality flag of 2 (dots) or 5 (crosses).

Table 2. Comparison of instrument performance measuring CFC-12.

\begin{tabular}{llll}
\hline System & Medusa-Aqua system & PT-GC-ECD & PT-GC-ECD \\
\hline Instrument & Cracker Medusa-GC-MS & Syringe PT-GC-ECD & Cracker PT-GC-ECD \\
Workplace & Laboratory in Kiel & On board & Laboratory in Kiel \\
Purge efficiency (\%) & $99.5 \pm 0.5^{\mathrm{a}}$ & $99.2 \pm 3.6^{\mathrm{b}}$ & $99.6 \pm 0.1^{\mathrm{c}}$ \\
Precision (\%) & 0.4 & 0.3 & 1.4 \\
Sampling volume (L) & $\sim 1.3$ & $\sim 0.3$ & $\sim 0.3$ \\
Measured compound & CFCs, HCFCs, HFCs, PFCs, etc. & $\mathrm{CFC}-12, \mathrm{SF}_{6}, \mathrm{SF}_{5} \mathrm{CF}_{3}$ & $\mathrm{CFC}-12, \mathrm{SF}_{6}, \mathrm{SF}_{5} \mathrm{CF}_{3}$ \\
\hline
\end{tabular}

${ }^{a}$ After purging three times. ${ }^{b}$ After purging once. ${ }^{c}$ After purging twice.

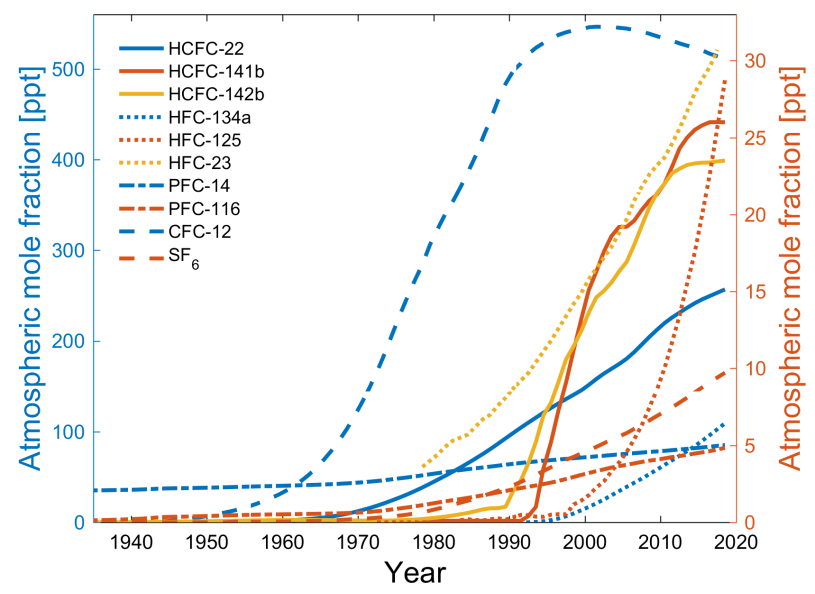

Figure 5. Atmospheric histories of HCFC-22, HCFC-141b, HCFC142b, HFC-134a, HFC-125, HFC-23, PFC-14, PFC-116, CFC-12, and $\mathrm{SF}_{6}$ in the Northern Hemisphere. HCFC-22, HFC-134a, PFC14 , and CFC-12 share the left $y$-axis scale; other compounds share the right $y$-axis scale.
$\Delta / \Gamma$ ratio of the TTD, with a range of $0.2-1.8$, corresponds to the proportion of advective transport and eddy-diffusive characteristics of the mixing processes for a water parcel; the higher the $\Delta / \Gamma$ ratio, the more dominant the diffusion and vice versa. For more details on the TTD model and mean age, see Sect. S4 and Figs. S9-S10.

\section{Results}

\subsection{Historical surface saturation in the Mediterranean Sea}

The historical surface saturation (together with the atmospheric history) of transient tracers is important to constrain the input function. To determine this for the Mediterranean Sea, we calculated seawater saturation in the winter mixed layer (WML) from historical cruise data. The depths of the WMLs in summer and winter are shown in Fig. 7 for two examples of potential density profiles. It is the saturation during winter that is relevant for deep and intermediate water formation, and thus for the input functions, rather than the one in the summer mixed layer. Therefore, only the WML 

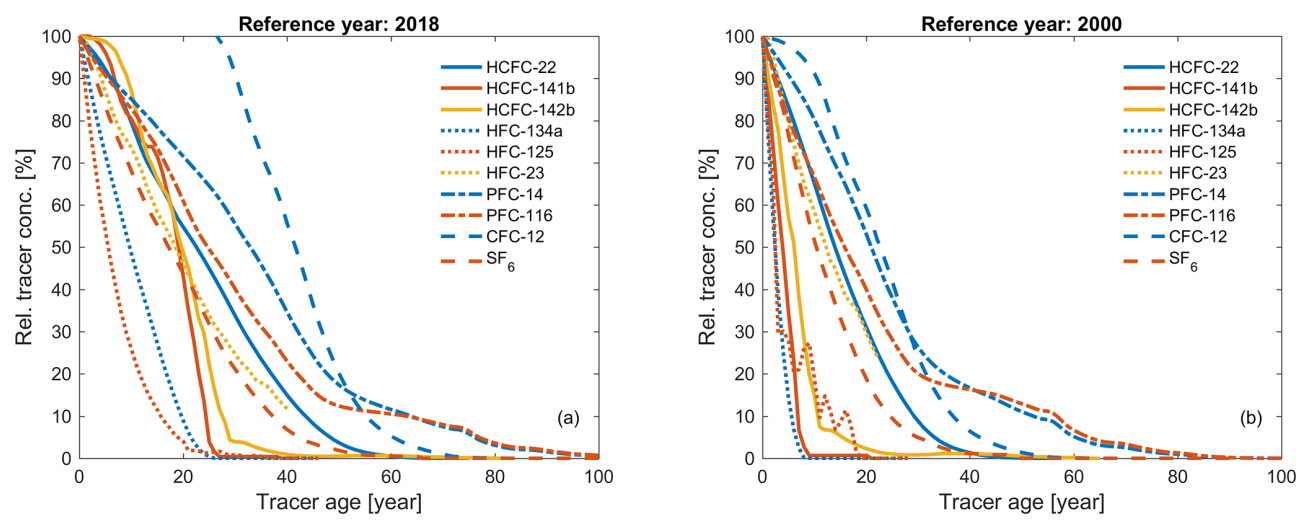

Figure 6. Relative tracer concentrations in percent (i.e., normalized to the contemporaneous atmospheric concentrations) and corresponding tracer age for HCFC-22, HCFC-141b, HCFC-142b, HFC-134a, HFC-125, HFC-23, PFC-14, PFC-116, CFC-12, and SF 6 in the Northern Hemisphere for two sampling years: (a) 2018 and (b) 2000.

was considered in the calculation of historical surface saturation for all cruises. The depth ranges of WMLs (Fig. S8) and the saturation for $\mathrm{CFC}-12$ and $\mathrm{SF}_{6}$ (Fig. 8) were determined by profiles of temperature, potential density, and the CFC-12 and $\mathrm{SF}_{6}$ concentration for every historical cruise in the Mediterranean Sea from 1987 to 2018 (Schneider et al., 2014; Li and Tanhua, 2020). Since no clear trend over time could be described, we averaged the mean seawater saturation from every single cruise and determined the historical surface saturation to be $94 \pm 6 \%$ and $94 \pm 4 \%$ for CFC- 12 and $\mathrm{SF}_{6}$, respectively. For CFC-12, this is different from the situation in the North Atlantic Ocean (Tanhua et al., 2008) and could be an indication of the different oceanographic settings in which the inflowing Atlantic Water (to the Mediterranean Sea) takes a long time to equilibrate with the atmosphere. The constant undersaturation through time is then mainly a function of rapid cooling during winter and entrainment of water from below rather than a rapid change in the atmospheric concentration that can drive undersaturation that varies over time. For the following calculations of ages and evaluation of stability, the historical surface saturations are assumed to be a constant $94 \%$ for all tracers in this study, as no data exist to determine the historical surface saturation of selected HCFCs and HFCs in the Mediterranean Sea.

\subsection{Observations of the Medusa tracers in the Mediterranean Sea}

Based on the reasonable correlation between CFC-12 observations from the Medusa-Aqua system and the onboard PTGC-ECD system (Sect. 3.5), we can move on and interpret the profiles of the Medusa tracers. Observations of CFC12 and $\mathrm{SF}_{6}$ from profiles 51, 83, and 105 measured by the PT-GC-ECD and those of CFC-12, HCFC-22, HCFC-141b, HCFC-142b, HFC-134a, and HFC-125 from the nearby profiles 52, 84, and 106 measured by the Medusa-Aqua system are shown in Fig. 9. The concentrations of Medusa tracers
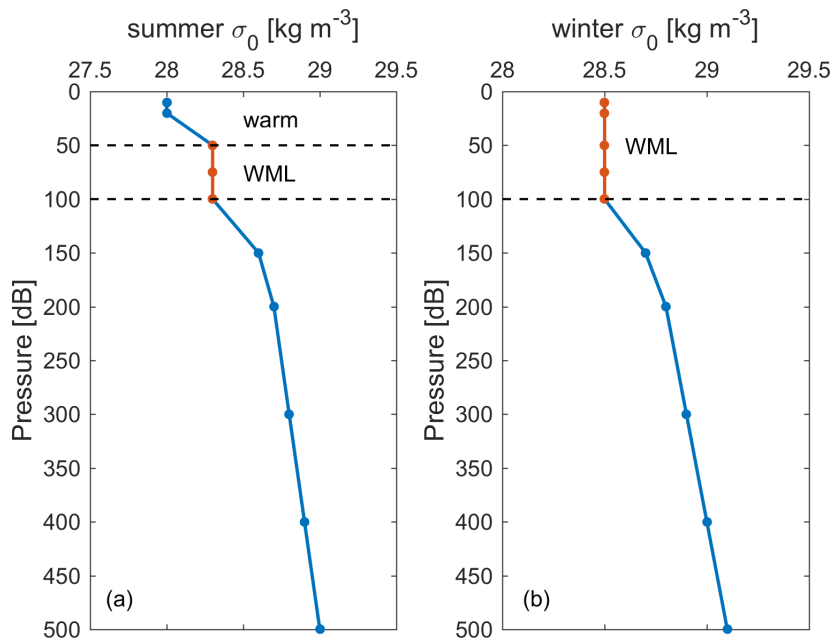

Figure 7. Example of the winter mixed layer (WML) depth (marked as red) determined in (a) summer and (b) winter in potential density $\left(\sigma_{0}\right)$ profiles specifically for historical surface saturation calculation.

decreased from the surface to the intermediate layer and then increased in the deep layer, which is consistent with our expectations of tracer concentrations, indicating well-ventilated Mediterranean deep waters as interpreted by $\mathrm{CFC}-12$ and $\mathrm{SF}_{6}$ (Li and Tanhua, 2020).

\subsection{Surface saturation of Medusa tracers in seawater}

The surface saturation of seawater can be an indicator of the stability of a compound in surface seawater or the correctness of the seawater solubility function. However, saturation is influenced by multiple parameters, such as partial pressures in the atmosphere and surface seawater, the airsea exchange velocity, the solubility and diffusivity of the gas, bubble injection and/or vertical mixing, and the temperature dependence of these parameters (Lobert et al., 1995; 

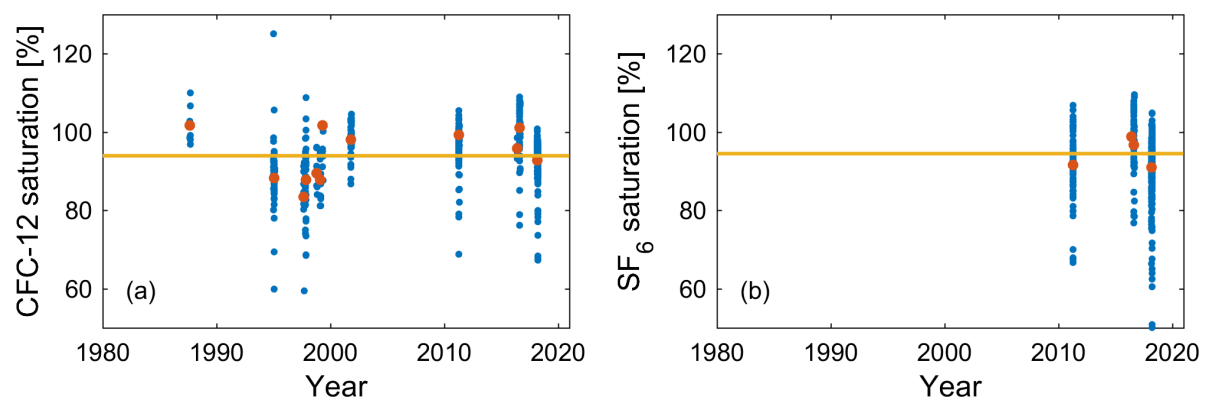

Figure 8. Historical surface saturations in winter mixed layers (blue solid circles) for (a) $\mathrm{CFC}-12$ from 12 cruises in $1987-2018$ and (b) $\mathrm{SF}_{6}$ from 4 cruises in the Mediterranean Sea (Li and Tanhua, 2020). Red solid circles denote the means of seawater saturation for each cruise, and the yellow lines $(94 \%)$ are the means of seawater saturation from all cruises.

Butler et al., 2016). In the Mediterranean Sea, we flagged all surface samples as suspect due to discrepancies between CFC-12 concentrations as measured by the Medusa-Aqua system and PT-GC-ECD. We therefore turn to the samples collected in the Baltic Sea, for which the seawater saturation of CFC-12 and the Medusa tracers in one surface sample as well as two bottom samples is shown in Table 3 . Note that the bottom water at this site is ventilated on an annual basis. The averaged saturations for the Baltic seawater samples are CFC-12 (122 $\pm 8 \%)$, HCFC-22 (77 $\pm 8 \%)$, HCFC-141b (74 $\pm 12 \%)$, HCFC-142b (114 $\pm 2 \%)$, HFC134a $(125 \pm 23 \%)$, and HFC-125 (252 $\pm 35 \%)$.

\subsection{Stability based on interior ocean observations}

In order to validate the stability of HCFCs and HFCs, the concentrations of CFC-12 from the adjacent PT-GC-ECD measurements for the Mediterranean samples are vertically interpolated by using a piecewise cubic hermite interpolating method on potential density surfaces and averaged by the arithmetic mean of the interpolated profiles (Tanhua et al., 2010; Schneider et al., 2014). Then the concentrations of HCFC-22, HCFC-141b, HCFC-142b, HFC-134a, HFC-125, and $\mathrm{SF}_{6}$ (measured by the PT-GC-ECD) are plotted against the (interpolated) CFC-12 for the Mediterranean and Baltic samples (Fig. 10). The concentrations of the Medusa tracers from the recent (usually shallow) layers are located in the upper right corner, with older (usually deep) samples near the lower left in Fig. 10. In the figure, we added the atmospheric history of the Medusa tracers vs. CFC-12, the theoretical mixing line between contemporary and pre-industrial concentrations (boundary line to 2018), and the theoretical mixing lines assuming an IG-TTD with $\Delta / \Gamma=0.2-1.8$. All samples will have to fall between the first two lines (i.e., the stability area) if the tracer is conservative in seawater by referring to previous methods (Huhn et al., 2001; Roether et al., 2001). Compounds for which the samples fall below the "stability area" are not stable (assuming that CFC-12 is stable), and for samples above it, there are issues with values that are too high (see below). For instance, HCFC-22 is found in the lower part of the stability area (samples would fall on this lowest line if there were no mixing but only advection in the ocean); HCFC-141b, HFC-125, and $\mathrm{SF}_{6}$ are well within the allowed ranges, whereas HCFC-142b and HFC-134a are around or above the upper boundary.

The increased ventilation of the (western) Mediterranean Sea during the last decade tends to result in different effects on CFC-12, which is decreasing in the atmosphere, and the Medusa tracers with increasing atmospheric concentrations. This argument suggests that we could see slightly higher than expected concentrations (similar to $\mathrm{SF}_{6}$ ) for the Medusa tracers. This is exactly what we see for HCFC-142b (Fig. 10). We found that the $\Delta / \Gamma$ ratio determined by the CFC-12-HCFC$141 \mathrm{~b}$ and CFC-12-HCFC-142b tracer pairs are similar to that of the $\mathrm{CFC}-12-\mathrm{SF}_{6}$ pair, indicating promising tracer pairs. The higher than expected concentration of HFC-134a may be caused by (1) contamination during sampling or measurement in the laboratory, (2) problems with solubility functions, and/or (3) some other issues within the measurements in the laboratory causing our measurements to be too high.

Although the assumption of time-invariant ventilation is not valid for the Mediterranean Sea, the TTD model can produce indicative results to understand the mean ages estimated from Medusa tracers (assuming $\Delta / \Gamma=1.0$ ) and their comparison to those estimated from $\mathrm{CFC}-12$ and $\mathrm{SF}_{6}$; see Sects. S4-S5 and Figs. S9-S11.

\section{Discussion}

The results from this study based on interior ocean observations can be used to evaluate the stability and further determine the potential of the Medusa tracers as oceanic transient tracers; as such, they are dependent on reasonably accurate measurements. The comparison between the mean ages calculated from the Medusa tracers and CFC-12 is sensitive to the assumed shape of the TTD and the differences in input history that make them respond differently to the timevariant ventilation of the (western) Mediterranean Sea. As a component of the input function, the historical surface satu- 
Table 3. Seawater surface saturations (\%) of CFC-12, HCFC-22, HCFC-141b, HCFC-142b, HFC-134a, and HFC-125 in profile 30 from cruise AL516 (measured by the Medusa-Aqua system) in the Baltic Sea.

\begin{tabular}{lrrrrrrr}
\hline Profile & $\begin{array}{r}\text { Pressure } \\
(\mathrm{dbar})\end{array}$ & CFC-12 & HCFC-22 & HCFC-141b & HCFC-142b & HFC-134a & HFC-125 \\
\hline 30 & 1.6 & 132 & 68 & 61 & 115 & 150 & 287 \\
30 & 23.5 & 118 & 79 & 84 & 112 & 105 & 218 \\
30 & 23.5 & 117 & 83 & 77 & 115 & 120 & 250 \\
\hline
\end{tabular}
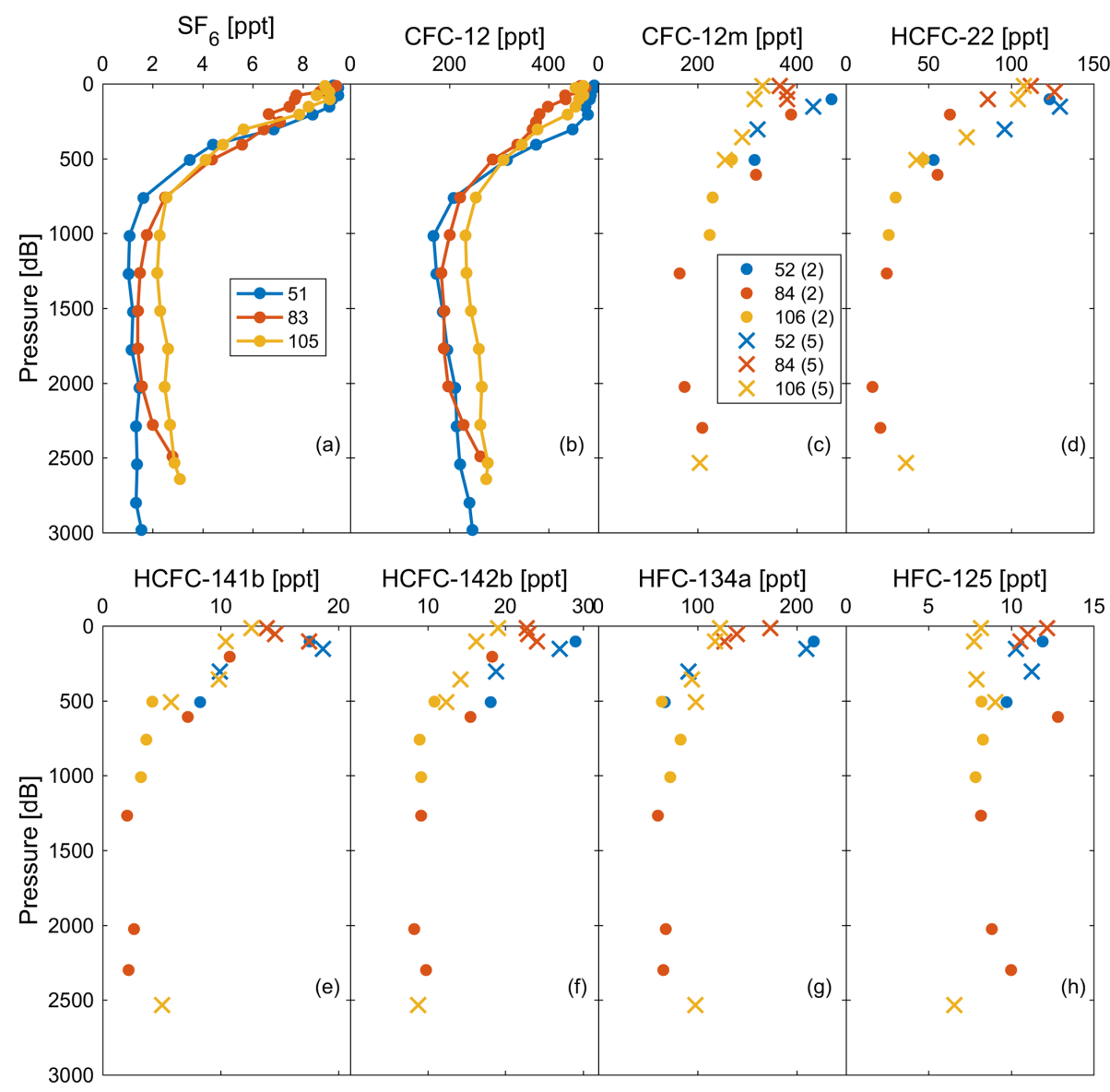

Figure 9. Observations of (a) $\mathrm{SF}_{6}$ and (b) CFC-12 in profiles 51, 83, and 105 measured by the PT-GC-ECD; (c) CFC-12 (marked as CFC-12m), (d) HCFC-22, (e) HCFC-141b, (f) HCFC-142b, (g) HFC-134a, and (h) HFC-125 in profiles 52, 84, and 106 measured by the Medusa-Aqua system. For an explanation of the values (2 and 5) and symbols (dots and crosses), refer to Fig. 4.

ration has been estimated to be $94 \%$; the atmospheric histories of the Medusa tracers have been given by Li et al. (2019), who also used indirect methods to estimate the solubility functions. HCFC-22, HCFC-141b, HCFC-142b, HFC-134a, and HFC-125 can be measured by the Medusa-Aqua system. Based on the combined results from Li et al. (2019) and this study, the potential of the Medusa tracers as transient tracers in the ocean is summarized in Table 4 by mainly evaluating their atmospheric history, seawater solubility, feasibility of measurement, and stability in seawater.
CFC-12. This tracer is included as a reference since it is a commonly used transient tracer. The atmospheric history of CFC-12 is well-documented (Walker et al., 2000; Bullister, 2015), and the seawater solubility function is wellestablished (Warner and Weiss, 1985). In addition, CFC-12 has been observed for several decades by using mature analytical techniques, and its stability in warm waters and/or poorly oxygenated waters has been proven. However, the decreasing atmospheric history of CFC-12 limits its ability as an oceanic transient tracer - it has only two bold stars in the column "Atmospheric history" since it is well-established but 

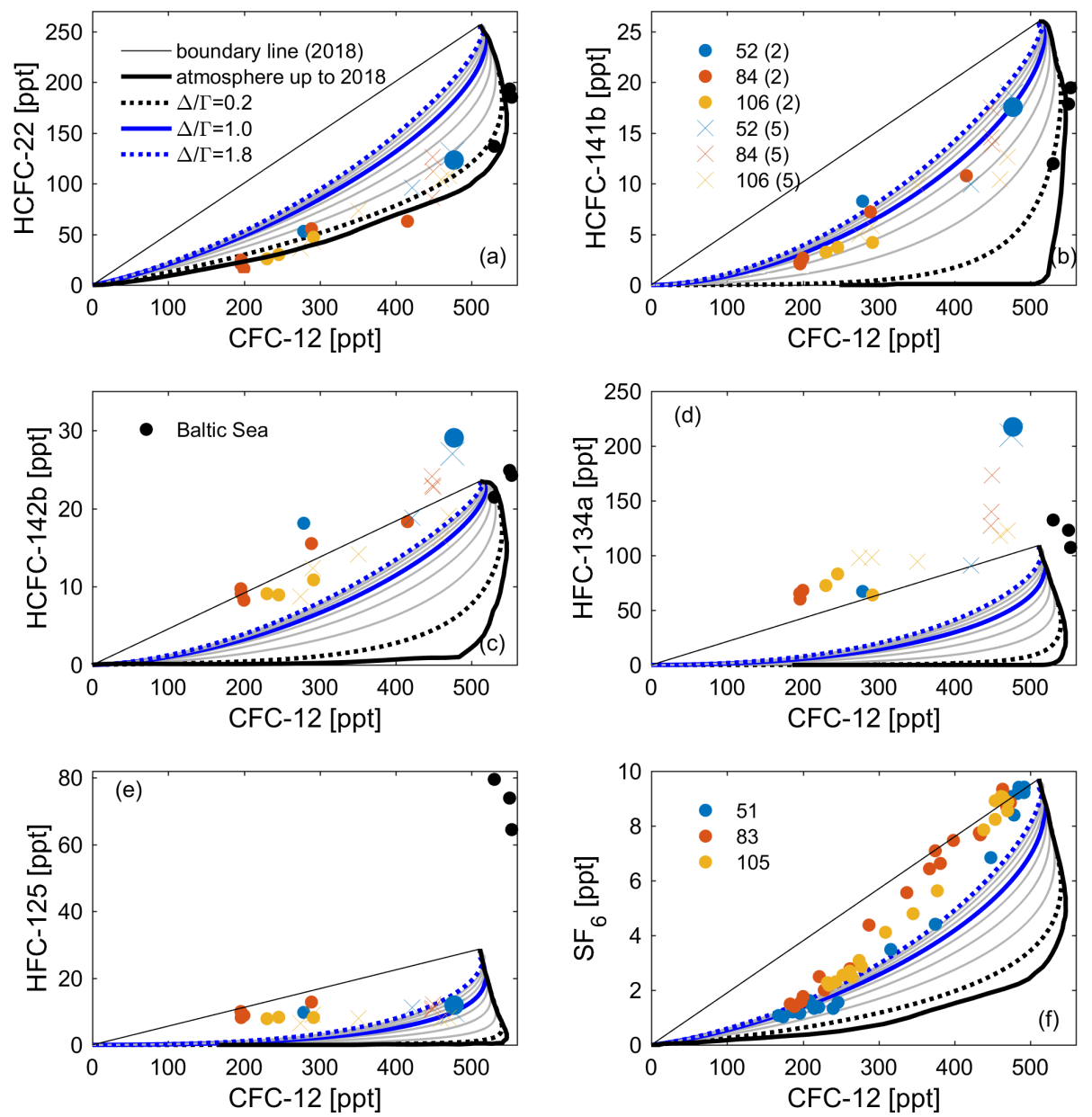

Figure 10. Observations of (a) HCFC-22, (b) HCFC-141b, (c) HCFC-142b, (d) HFC-134a, and (e) HFC-125 in profiles 52, 84, and 106 measured by the Medusa-Aqua system and (f) $\mathrm{SF}_{6}$ in profiles 51, 83, and 105 measured by PT-GC-ECD plotted against (interpolated) CFC12 based on measurements by PT-GC-ECD in the Mediterranean Sea. Observations of tracers from cruise AL516 in the Baltic Sea have been added (black dots). The thick black line is the atmospheric history of the tracer pair $(\Delta / \Gamma=0.0)$, and the thin black line is the theoretical mixing line between contemporary and pre-industrial concentrations. The theoretical mixing lines assuming an IG-TTD with $\Delta / \Gamma=0.2-1.8$ have also been added. The values of the top two points of profile 52 are bigger to identify the samples in shallow layers. For an explanation of the values (2 and 5) and symbols (dots and crosses), refer to Fig. 4.

still not ideal as an oceanic transient tracer for recently ventilated waters.

$H C F C$-22. The increasing atmospheric history is wellestablished by a combination of model results and observations ( $\mathrm{Li}$ et al., 2019). The seawater solubility function has been constructed by combining the CGW (Clark-GlewWeiss) model using experimental freshwater solubility data and another model (poly-parameter linear free-energy relationships, pp-LFERs) using salting-out coefficients (Li et al., 2019). The results for freshwater solubility matched those published by Deeds (2008) using measurements and CGW model results between 298 and $348 \mathrm{~K}$ as well as those published in Abraham et al. (2001) using observations and ppLFERs model results at 298 and $310 \mathrm{~K}$. The confidence in the seawater solubility was marked as medium due to lack of direct experimental seawater solubility data to verify the func- tion. HCFC-22 has been measured on several cruises (Lobert et al., 1996; Yvon-Lewis et al., 2008) by GC-ECD and GCMS instruments and in this study by the Medusa-Aqua system. The stability was evaluated by comparison to CFC-12 observations. The clustering of HCFC-22 values in the lower range (Fig. 10) could be an indication of slow degradation in seawater, which is also supported by the weak hydrolysis of HCFC-22 in tropical and subtropical waters reported by Lobert et al. (1995). Therefore, HCFC-22 was determined to be unstable in warm waters; additional experiments are needed to evaluate the stability, especially in poorly oxygenated waters. In addition, HCFC-22 can be replaced by $\mathrm{SF}_{6}$ as a transient tracer since they have similar atmospheric histories (Figs. 5 and 6). All of this indicates that HCFC-22 might not be suitable as a new transient tracer in the warm 
Table 4. Evaluating the possibilities of selected HCFCs, HFCs, and PFCs as transient tracers in the ocean in terms of four aspects.

\begin{tabular}{lccccc}
\hline Compound & $\begin{array}{c}\text { Atmospheric } \\
\text { history }\end{array}$ & $\begin{array}{c}\text { Solubility } \\
\text { in seawater }\end{array}$ & $\begin{array}{c}\text { Feasibility } \\
\text { of measurement } \\
\text { in seawater }\end{array}$ & $\begin{array}{c}\text { Stability } \\
\text { in seawater }\end{array}$ & $\begin{array}{c}\text { Possibility } \\
\text { to be a } \\
\text { transient tracer }\end{array}$ \\
\hline CFC-12 & $* * *$ a & $* * *$ & $* * *$ & $* * *$ & $* * *$ \\
HCFC-22 & $* * *$ & $* *$ & $* * *$ & $* *$ & $* *$ \\
HCFC-141b & $* * *$ & $*$ & $* * *$ & $* *$ & $* *$ \\
HCFC-142b & $* * *$ & $* *$ & $* * *$ & $* *$ & $* *$ \\
HFC-134a & $* * *$ & $* *$ & $* *$ & $* *$ & $* *$ \\
HFC-125 & $* * *$ & $*$ & $*$ & $*$ & $*$ \\
HFC-23 & $* *$ & $* *$ & $*$ & $*$ & $*$ \\
PFC-14 & $* * *$ & $* *$ & $*$ & $* * *$ & $*$ \\
PFC-116 & $* * *$ & $*$ & $*$ & $* * *$ & $* *$ \\
\hline
\end{tabular}

${ }^{a}$ The total number of (bold and regular) stars represents current knowledge. One star means "largely unknown", two stars indicate "reasonably well-resolved", and three stars indicate "well-documented or well-resolved". The number of bold stars represents the possibility of a compound as a transient tracer through current assessments. For instance, the atmospheric history for CFC-12 got three stars since we know this very well, but only two of those are bold since its atmospheric concentrations are decreasing after experiencing a continuous increase.

ocean, for instance in the Mediterranean Sea, but it could be used for colder waters.

$H C F C-141 b$. The atmospheric history is reliably reconstructed (Li et al., 2019). However, the seawater solubility function was constructed for the first time (Li et al., 2019), and the freshwater solubility only matched the data presented in Abraham et al. (2001) at the two temperatures. The low surface saturation measured in the Baltic Sea suggests that there is likely an issue with the solubility function. HCFC$141 \mathrm{~b}$ has been previously measured on cruises (Lobert et al., 1996; Yvon-Lewis et al., 2008) and also in this study; thus, we have high confidence in the ability to measure this compound. HCFC-141b is identified to be potentially stable in seawater since its concentrations are in the expected range in the interior ocean (Fig. 10). The input function of HCFC$141 \mathrm{~b}$ is different enough from the traditional transient tracers to provide additional information, but since its atmospheric history started to decrease in 2017 (Li et al., 2019), the use of HCFC-141b as a transient tracer for "young" waters will be compromised. All of this indicates that HCFC-141b probably has limited potential as a transient tracer in the future.

$H C F C-142 b$. The confidence in the atmospheric history is similar to that of HCFC-141b for the same reasons, while the high HCFC-142b saturation of samples from the Baltic Sea supports the medium confidence in the seawater solubility function. HCFC-142b has been measured on some cruises (Lobert et al., 1996; Yvon-Lewis et al., 2008) and also in this study, giving us confidence to accurately measure this compound. We have medium confidence in our ability to estimate the stability of HCFC-142b because of higher than expected concentrations in the interior ocean (Fig. 10), although this could be linked to the slightly high saturation observed. The input function of HCFC-142b is different from that of most other tracers (only similar to that of HCFC-141b but with a longer time range). Consequently, HCFC-142b has high potential to be used as a transient tracer.

$H F C$-134a. We have high and medium confidence in the atmospheric history and seawater solubility function (Li et al., 2019), respectively. Although the estimated seawater solubility function was constructed based on the modeled salting-out coefficients and the experimental freshwater solubility (Li et al., 2019) that matched both the observations (Deeds, 2008) and model results (Abraham et al., 2001), we have only medium confidence in the seawater solubility function due to the lack of experimental seawater solubility data. However, the samples from the Baltic Sea suggest that the solubility function seems reasonable. HFC-134a was measured by Ooki and Yokouchi (2011) using GC-MS and in this study by the Medusa-Aqua system. It could indicate contamination issues due to higher than expected concentrations (see Sect. 5.4). We have medium confidence in the stability of HFC-134a, also because of the higher than expected concentrations (Fig. 10). The compound is not identified as unstable, and Fig. 10 suggests that the HFC134a is stable (see Sect. 5.4). In addition, HFC-134a can only be used as a tracer for young waters due to its short atmospheric history. Based on all these discussions, HFC-134a has medium potential to be an oceanic transient tracer.

HFC-125. The atmospheric concentrations of HFC-125 in the early 1990s are unclear (Fig. 6), possibly related to uncertainties in the reconstruction, although this only marginally influences its ability as a transient tracer. Three seawater solubility functions of HFC-125 have been constructed ( $\mathrm{Li}$ et al., 2019), although only two of them were considered; function 1 is supported by freshwater solubility results from Deeds (2008) and a stability analysis based on comparison to CFC-12 in this study (Fig. 10), whereas the observations and model results from Abraham et al. (2001) support function 3. This leads to low confidence in the seawater solubility func- 
tion of HFC-125. We also consider the ability to measure HFC-125 low since this compound has been measured for the first time in seawater in this study, and we find almost no vertical gradient (Fig. 9), which is unexpected. Furthermore, observed HFC-125 concentrations in freshwater are inconsistent as indicated by three freshwater solubility functions $(\mathrm{Li}$ et al., 2019), which suggests unresolved issues with its measurements in water. Due to the poorly defined solubility and difficulties in measurement, it is difficult to assess the stability of HFC-125 in this work. Also, HFC-125 can only be a tracer for young water due to its short atmospheric history. Therefore, we consider HFC-125 to have low potential as a transient tracer in the ocean, although this might be remedied by experimentally determining the seawater solubility function and solving possible measurement issues.

$H F C-23$. HFC-23 could not be reliably measured in our system due to unstable nonzero blanks (see Sect. 3.4). Therefore, we can not reliably assess the stability of HFC- 23 in seawater, and we have low confidence in our ability to measure this compound, although the blank problem might be solved by a different instrument configuration. The atmospheric history of HFC-23 has been constructed ( $\mathrm{Li}$ et al., 2019; Simmonds et al., 2018), but we have only medium confidence as it does not start from zero (Simmonds et al., 2018) due to limited data. We have only medium confidence in the seawater solubility function for the same reason as for HFC134a. That is, the freshwater solubility function matched results from Deeds (2008) and Abraham et al. (2001), but the seawater solubility function was not constructed by experimental seawater solubility data. In consequence, unknown stability and current issues with measurements lead to the overall assessment that HFC-23 has low potential as a transient tracer in the ocean.

$P F C-14$ and $P F C-116$. The increasing atmospheric histories of PFC-14 and PFC-116 are well-established (Li et al., 2019; Trudinger et al., 2016). The seawater solubility functions have been constructed with medium confidence for PFC-14 as it matches both seawater measurements (Scharlin and Battino, 1995) and freshwater solubility (Clever et al., 2005; Abraham et al., 2001). In contrast, low confidence for the solubility function for PFC-116 is attributed to its freshwater solubility only matching that from Deeds (2008) but not the theoretical assessment from Abraham et al. (2001). PFC-14 and PFC-116 are very stable in the environment but cannot easily be measured in seawater because of the low solubility (Li et al., 2019), i.e., low concentration in seawater. The high stability and long atmospheric histories make PFCs potentially promising transient tracers in the ocean, although measurements are challenging. A possibility would be to use an ECD that has a high sensitivity for C-F bonds, but with the additional complication of co-elution on the chromatogram.

\section{Conclusions and outlook}

This study, combined with the study by Li et al. (2019), provides a method to identify and evaluate whether a compound is suitable for use as a transient tracer in the ocean. Selected HCFCs, HFCs, and PFCs were evaluated for their potential as transient tracers. The evaluation mainly considered four aspects: input function (including atmospheric history and historical surface saturation), seawater solubility, feasibility of measurement, and stability in seawater. We also considered how Medusa tracers with different atmospheric histories complement each other when constraining ocean ventilation. For these purposes, we modified an existing analytical system for seawater measurements and observed seawater concentrations of HCFC-22, HCFC-141b, HCFC-142b, HFC-134a, and HFC-125. Unfortunately, the poorly soluble PFCs could not be successfully measured with our current analytical system.

Through a comprehensive evaluation, we conclude that HCFC-22 is unlikely to be a transient tracer in warm waters, whereas HFC-23 cannot be evaluated as a transient tracer because of the lack of information. Fortunately, these two compounds can be substituted by $\mathrm{SF}_{6}$ that has a similar atmospheric history. On the other hand, both HCFC$141 \mathrm{~b}$ and HCFC-142b currently show high potential as transient tracers. Considering their similar atmospheric histories and the decreasing atmospheric mole fraction of HCFC141b, HCFC-142b should be further evaluated by obtaining more reliable solubility and stability information in seawater. HFC-134a and HFC-125 show medium and low potential as transient tracers, respectively. The former shows medium potential because of higher than expected concentrations, pointing to issues with the seawater solubility function and/or the measurements, but it is not identified to be unstable. The latter shows low potential due to the lack of information on solubility, stability, and feasibility of measurement in seawater. Considering their similar atmospheric histories, HFC-134a is a more promising candidate as a transient tracer. Last but not least, PFC-14 and PFC-116 show large potential as transient tracers once their accurate measurement in seawater is resolved. The high stability and long atmospheric history make it worthwhile to explore improved analytical methods, whether it implies using a more sensitive detector or larger samples.

The main result from this study is that although a couple of the investigated tracers might be useful as oceanic tracers, at least under some circumstances such as in cold waters, none of the tracers would be fully qualified at this time. Although we have a good handle on the input function in the atmospheric history, we recognize that targeted work is needed for all compounds to better constrain the solubility. For stability, we have an idea regarding which ones are possibly stable, but more work is needed here too (possibly laboratory experiments under controlled conditions). There are limitations in the current configuration of the analytical techniques as 
described, and additional efforts are needed to improve the system. In summary, we are not quite yet in the position to recommend targeted observations of these tracers, but this study provides a useful summary of the current knowledge, including the new research reported in this paper, to further guide more targeted experiments and studies.

Future work will include further evaluating the potential transient tracers identified in this study and constraining ventilation in the global ocean by combining multiple transient tracers using suitable models to describe the transit time distribution. The next steps include experiments in controlled laboratory conditions to construct seawater solubility functions and explore the stability of the compounds, in particular for warm and/or oxygen-depleted seawater. Additional work on improving the measurement capacity for PFC-14 and PFC-116 could include modifying the Medusa system according to Arnold et al. (2012) or possibly using a more sensitive detector (i.e., ECD). The reliability and reproducibility of the measurements for routine use should be improved, possibly by using the vacuum-sparge method by Law et al. (1994) that would speed up the gas extraction and reduce the number of purge cycles needed.

Data availability. Cruise data on historical surface saturation for CFC-12 and $\mathrm{SF}_{6}$ in the Mediterranean Sea (Sect. 5.1) are from https://www.nodc.noaa.gov/ocads/oceans/Coastal/Meteor_Med_ Sea.html (Li and Tanhua, 2020). Observations of CFC-12 and $\mathrm{SF}_{6}$ measured by the PT-GC-ECD and those of CFC-12, HCFC-22, HCFC-141b, HCFC-142b, HFC-134a, and HFC-125 measured by the Medusa-Aqua system in seawater from cruises MSM72 and AL516 are shown in Table S7.

Supplement. The supplement related to this article is available online at: https://doi.org/10.5194/os-17-509-2021-supplement.

Author contributions. TT conducted the sampling from cruise MSM72. PL developed the instrument and carried out the measurements. PL interpreted the data and analyzed the results based on the discussion with TT. PL wrote the paper with contributions from TT.

Competing interests. The authors declare that they have no conflict of interest.

Acknowledgements. We acknowledge the great support by the captain, crew, and scientists from expeditions MSM18/3, MSM23, M130, NORC2017-09, KBP523, KBP524, MSM72, and AL516 for the development of the Medusa-Aqua system. Special thanks go to Boie Bogner and Tim Steffens for their technical support with the instrumentation for the Medusa-Aqua system; Tim Steffens, Dennis Booge, Melf Paulsen, and Li Zhou for taking samples from cruise AL516 in the Baltic Sea; Minggang Cai, Peng Huang, and Weimin Wang for supporting sampling at sea on cruise NORC2017-
09 in the western Pacific Ocean; and Lennart Gerke for measuring equilibrated seawater samples from the tropical Atlantic Ocean. The authors also gratefully acknowledge support through the scholarship program from the China Scholarship Council (CSC). In addition, the authors thank the topical editor and reviewers for their valuable suggestions and comments to help improve this paper.

Financial support. This research has been supported by the GEOMAR Innovationsfonds Technologie-Seed-Funding (grant no. Transient Tracers 70090/03) and the China-Germany Joint Research Program (Programm des Projektbezogenen Personenaustauschs, PPP) (grant no. D1820).

The article processing charges for this open-access publication were covered by a Research Centre of the Helmholtz Association.

Review statement. This paper was edited by Piers Chapman and reviewed by four anonymous referees.

\section{References}

Abraham, M. H., Gola, J. M., Cometto-Muñiz, J. E., and Cain, W. S.: Solvation properties of refrigerants, and the estimation of their water-solvent and gas-solvent partitions, Fluid Phase Equilib., 180, 41-58, https://doi.org/10.1016/S0378-3812(00)005112, 2001.

Aggarwal, P. K.: Isotope Methods for Dating Old Groundwater, edited by: Suckow, A., Aggarwal, P., and Araguas-Araguas, L., International Atomic Energy Agency, Vienna, 357 pp., 2013.

Arnold, T., Mühle, J., Salameh, P. K., Harth, C. M., Ivy, D. J., and Weiss, R. F.: Automated Measurement of Nitrogen Trifluoride in Ambient Air, Anal. Chem., 84, 4798-4804, https://doi.org/10.1021/ac300373e, 2012.

Beyer, M., van der Raaij, R., Morgenstern, U., and Jackson, B.: Potential groundwater age tracer found: Halon-1301 $\left(\mathrm{CF}_{3} \mathrm{Br}\right)$, as previously identified as $\mathrm{CFC}-13\left(\mathrm{CF}_{3} \mathrm{Cl}\right)$, Water Resour. Res., 50, 7318-7331, https://doi.org/10.1002/2014WR015818, 2014.

Booge, D.: FS Alkor Cruise Report, Cruise AL516, 12.09.201822.09.2018. Alkor-Berichte, AL516, GEOMAR HelmholtzZentrum für Ozeanforschung Kiel, Kiel, Germany, 25 pp., https://doi.org/10.3289/CR_AL516, 2018.

Bullister, J. and Weiss, R.: Determination of $\mathrm{CCl}_{3} \mathrm{~F}$ and $\mathrm{CCl}_{2} \mathrm{~F}_{2}$ in seawater and air, Deep-Sea Res. Pt. A, 35, 839-853, https://doi.org/10.1016/0198-0149(88)90033-7, 1988.

Bullister, J. L.: Atmospheric Histories (1765-2015) for CFC-11, CFC-12, CFC-113, CCl4, SF6 and N2O, NDP-095, 1-23, available at: http://cdiac.ess-dive.lbl.gov/ftp/oceans/CFC_ATM_Hist/ CFC_ATM_Hist_2015 (last access: 31 March 2021), Carbon Dioxide Information Analysis Center, Oak Ridge National Laboratory, US Department of Energy, 2015.

Bullister, J. L. and Tanhua, T.: Sampling and Measurement of Chlorofluorocarbon and Sulfur Hexafluoride in Seawater GO-SHIP Repeat Hydrography Manual: A Collection of Expert Reports and Guidelines. IOCCP Report, 14. GO-SHIP (Unesco/IOC), Paris, France, 1-11, 2010. 
Bullister, J. L. and Wisegarver, D. P.: The shipboard analysis of trace levels of sulfur hexafluoride, chlorofluorocarbon-11 and chlorofluorocarbon-12 in seawater, Deep-Sea Res. Pt. I, 55, 1063-1074, https://doi.org/10.1016/j.dsr.2008.03.014, 2008.

Bullister, J. L., Wisegarver, D. P., and Menzia, F. A.: The solubility of sulfur hexafluoride in water and seawater, Deep-Sea Res. Pt. I, 49, 175-187, https://doi.org/10.1016/S0967-0637(01)00051-6, 2002.

Bullister, J. L., Wisegarver, D. P., and Sonnerup, R. E.: Sulfur hexafluoride as a transient tracer in the North Pacific Ocean, Geophys. Res. Lett., 33, L18603, https://doi.org/10.1029/2006GL026514, 2006.

Butler, J. H., Yvon-Lewis, S. A., Lobert, J. M., King, D. B., Montzka, S. A., Bullister, J. L., Koropalov, V., Elkins, J. W., Hall, B. D., Hu, L., and Liu, Y.: A comprehensive estimate for loss of atmospheric carbon tetrachloride $\left(\mathrm{CCl}_{4}\right)$ to the ocean, Atmos. Chem. Phys., 16, 10899-10910, https://doi.org/10.5194/acp-1610899-2016, 2016.

Carpenter, L. J., Reimann, S., Burkholder, J. B., Clerbaux, C., Hall, B. D., Hossaini, R., Laube, J. C., and Yvon-Lewis, S. A.: Scientific Assessment of Ozone Depletion: 2014, World Meteorological Organization, Geneva, 1.1-5.58, 2014.

Cicerone, R. J.: Atmospheric carbon tetrafluoride: A nearly inert gas, Science, 206, 59-61, https://doi.org/10.1126/science.206.4414.59, 1979.

Clever, H. L., Battino, R., Clever, H. L., Jaselskis, B., Clever, H. L., Yampol'skii, Y. P., Jaselskis, B., Scharlin, P., and Young, C. L.: IUPAC-NIST Solubility Data Series. 80. Gaseous Fluorides of Boron, Nitrogen, Sulfur, Carbon, and Silicon and Solid Xenon Fluorides in all Solvents, J. Phys. Chem. Ref. Data, 34, 201-438, https://doi.org/10.1063/1.1794762, 2005.

Deeds, D. A.: The Natural Geochemistry of Tetrafluoromethane and Sulfur Hexafluoride: Studies of Ancient Mojave Desert Groundwaters, North Pacific Seawaters and the Summit Emissions of Kilauea Volcano, PhD thesis, Scripps Institution of Oceanography, San Diego, 174 pp., 2008.

Ebser, S., Kersting, A., Stöven, T., Feng, Z., Ringena, L., Schmidt, M., Tanhua, T., Aeschbach, W., and Oberthaler, M. K.: ${ }^{39} \mathrm{Ar}$ dating with small samples provides new key constraints on ocean ventilation, Nat. Commun., 9, 5046, https://doi.org/10.1038/s41467-018-07465-7, 2018.

Hainbucher, D., Álvarez, M., Astray Uceda, B., Bachi, G., Cardin, V., Celentano, P., Chaikalis, S., del Mar Chaves Montero, M., Civitarese, G., Fajar, N. M., Fripiat, F., Gerke, L., Gogou, A., Guallart, E. F., Gülk, B., El Rahman Hassoun, A., Lange, N., Rochner, A., Santinelli, C., Steinhoff, T., Tanhua, T., Urbini, L., Velaoras, D., Wolf, F., and Welsch, A.: Physical and biogeochemical parameters of the Mediterranean Sea during a cruise with RV Maria S. Merian in March 2018, Earth Syst. Sci. Data, 12, 27472763, https://doi.org/10.5194/essd-12-2747-2020, 2020.

Hall, T. M. and Plumb, R. A.: Age as a diagnostic of stratospheric transport, J. Geophy. Res.-Atmos., 99, 1059-1070, https://doi.org/10.1029/93JD03192, 1994.

Holzer, M., Smethie Jr, W. M., and Ting, Y. H.: Ventilation of the Subtropical North Atlantic: locations and times of last ventilation estimated using tracer constraints from GEOTRACES Section GA03, J. Geophys. Res.-Oceans, 123, 2332-2352, 2018.

Huhn, O., Roether, W., Beining, P., and Rose, H.: Validity limits of carbon tetrachloride as an ocean tracer, Deep-Sea Res. Pt. I,
48, 2025-2049, https://doi.org/10.1016/S0967-0637(01)000048, 2001.

Law, C., Watson, A., and Liddicoat, M.: Automated vacuum analysis of sulphur hexafluoride in seawater: derivation of the atmospheric trend (1970-1993) and potential as a transient tracer, Mar. Chem., 48, 57-69, https://doi.org/10.1016/03044203(94)90062-0, 1994.

Li, P. and Tanhua, T.: Recent changes in deep ventilation of the Mediterranean Sea; evidence from long-term transient tracer observations, Front. Mar. Sci., 7, 594, https://doi.org/10.3389/fmars.2020.00594, 2020 (data available at: https://www.nodc.noaa.gov/ocads/oceans/Coastal/ Meteor_Med_Sea.html, last access: 31 March 2021).

Li, P., Mühle, J., Montzka, S. A., Oram, D. E., Miller, B. R., Weiss, R. F., Fraser, P. J., and Tanhua, T.: Atmospheric histories, growth rates and solubilities in seawater and other natural waters of the potential transient tracers HCFC-22, HCFC-141b, HCFC-142b, HFC-134a, HFC-125, HFC-23, PFC-14 and PFC-116, Ocean Sci., 15, 33-60, https://doi.org/10.5194/os-15-33-2019, 2019.

Lobert, J. M., Butler, J. H., Baring, T. J., Montzka, S. M., Myers, R. C., and Elkins, J. W.: OAXTC 92: Ocean/Atmosphere Exchange of Trace Compounds 1992: Oceanic measurements of HCFC-22, CFC-11, CFC-12, CFC-113, $\mathrm{CH} 3 \mathrm{CCl} 3, \mathrm{CCl} 4$, and $\mathrm{N}_{2} \mathrm{O}$ in the marine air and surface waters of the west Pacific Ocean $(\mathrm{Au}-$ gust 3-October 21, 1992), NOAA Technical Memorandum, ERL CMDL-9, 43 pp., 1995.

Lobert, J. M., Butler, J. H., Geller, L. S., Montzka, S. A., Yvon, S. A., Myers, R. C., and Elkins, J. W.: BLAST 94: Bromine Latitudinal Air/Sea Transect 1994, Report on Oceanic Measurements of Methyl Bromide and Other Compounds, NOAA Technical Memorandum ERL CMDL-10 (2/1996), available from NTIS, 5285 Port Royal Road, Springfield, VA 22161 USA, 1996.

Lu, Z. T., Schlosser, P., Smethie Jr., W. M., Sturchio, N. C., Fischer, T. P., Kennedy, B. M., Purtschert, R., Severinghaus, J. P., Solomon, D. K., Tanhua, T., and Yokochi, R.: Tracer applications of noble gas radionuclides in the geosciences, Earth-Sci. Rev., 138, 196-214, https://doi.org/10.1016/j.earscirev.2013.09.002, 2014.

Miller, B. R., Weiss, R. F., Salameh, P. K., Tanhua, T., Greally, B. R., Mühle, J., and Simmonds, P. G.: Medusa: A sample preconcentration and GC/MS detector system for in situ measurements of atmospheric trace halocarbons, hydrocarbons, and sulfur compounds, Anal. Chem., 80, 1536-1545, https://doi.org/10.1021/ac702084k, 2008.

Ooki, A. and Yokouchi, Y.: Determination of Henry's law constant of halocarbons in seawater and analysis of sea-to-air flux of iodoethane $\left(\mathrm{C}_{2} \mathrm{H}_{5} \mathrm{I}\right)$ in the Indian and Southern oceans based on partial pressure measurements, Geochem. J., 45, e1-e7, https://doi.org/10.2343/geochemj.1.0122, 2011.

Prinn, R. G., Weiss, R. F., Arduini, J., Arnold, T., DeWitt, H. L., Fraser, P. J., Ganesan, A. L., Gasore, J., Harth, C. M., Hermansen, O., Kim, J., Krummel, P. B., Li, S., Loh, Z. M., Lunder, C. R., Maione, M., Manning, A. J., Miller, B. R., Mitrevski, B., Mühle, J., O’Doherty, S., Park, S., Reimann, S., Rigby, M., Saito, T., Salameh, P. K., Schmidt, R., Simmonds, P. G., Steele, L. P., Vollmer, M. K., Wang, R. H., Yao, B., Yokouchi, Y., Young, D., and Zhou, L.: History of chemically and radiatively important atmospheric gases from the Advanced Global Atmospheric 
Gases Experiment (AGAGE), Earth Syst. Sci. Data, 10, 9851018, https://doi.org/10.5194/essd-10-985-2018, 2018.

Ravishankara, A., Solomon, S., Turnipseed, A. A., and Warren, R.: Atmospheric lifetimes of longlived halogenated species, Science, 259, 194-199, https://doi.org/10.1126/science.259.5092.194, 1993.

Roether, W., Klein, B., and Bulsiewicz, K.: Apparent loss of CFC113 in the upper ocean, J. Geophys. Res.-Oceans, 106, 26792688, https://doi.org/10.1029/1999JC000079, 2001.

Scharlin, P. and Battino, R.: Solubility of $\mathrm{CCl}_{2} \mathrm{~F}_{2}, \mathrm{CClF}_{3}$, $\mathrm{CF}_{4}$, and $\mathrm{CH}_{4}$ in Water and Seawater at 288.15-303.15 $\mathrm{K}$ and $101.325 \mathrm{kPa}$, J. Chem. Eng. Data, 40, 167-169, https://doi.org/10.1021/je00017a036, 1995.

Schneider, A., Tanhua, T., Roether, W., and Steinfeldt, R.: Changes in ventilation of the Mediterranean Sea during the past 25 year, Ocean Sci., 10, 1-16, https://doi.org/10.5194/os-10-12014, 2014.

Simmonds, P. G., Rigby, M., McCulloch, A., Vollmer, M. K., Henne, S., Mühle, J., O’Doherty, S., Manning, A. J., Krummel, P. B., Fraser, P. J., Young, D., Weiss, R. F., Salameh, P. K., Harth, C. M., Reimann, S., Trudinger, C. M., Steele, L. P., Wang, R. H. J., Ivy, D. J., Prinn, R. G., Mitrevski, B., and Etheridge, D. M.: Recent increases in the atmospheric growth rate and emissions of HFC-23 $\left(\mathrm{CHF}_{3}\right)$ and the link to HCFC$22\left(\mathrm{CHClF}_{2}\right)$ production, Atmos. Chem. Phys., 18, 4153-4169, https://doi.org/10.5194/acp-18-4153-2018, 2018.

Sousa, S. R. and Bialkowski, S. E.: Comparison of gas chromatography detection limits and relative responses of common alternative fluorocarbons using electron capture, atomic emission, and mass spectrometry detection, Anal. Chim. Acta, 433, 181-186, https://doi.org/10.1016/S0003-2670(01)00789-9, 2001.

Stöven, T.: Ventilation Processes of the Mediterranean Sea based on CFC-12 and SF6 measurements, Diploma thesis, ChristianAlbrechts-Universität, Kiel, Germany, 152 pp., 2011.

Stöven, T. and Tanhua, T.: Ventilation of the Mediterranean Sea constrained by multiple transient tracer measurements, Ocean Sci., 10, 439-457, https://doi.org/10.5194/os-10-4392014, 2014.

Stöven, T., Tanhua, T., Hoppema, M., and Bullister, J. L.: Perspectives of transient tracer applications and limiting cases, Ocean Sci., 11, 699-718, https://doi.org/10.5194/os-11-6992015, 2015.

Stöven, T., Tanhua, T., Hoppema, M., and von Appen, W.-J.: Transient tracer distributions in the Fram Strait in 2012 and inferred anthropogenic carbon content and transport, Ocean Sci., 12, 319333, https://doi.org/10.5194/os-12-319-2016, 2016.
Tanhua, T., Anders Olsson, K., and Fogelqvist, E.: A first study of $\mathrm{SF}_{6}$ as a transient tracer in the Southern Ocean, Deep-Sea Res. Pt. II, 51, 2683-2699, https://doi.org/10.1016/j.dsr2.2001.02.001, 2004

Tanhua, T., Waugh, D. W., and Wallace, D. W. R.: Use of $\mathrm{SF}_{6}$ to estimate anthropogenic $\mathrm{CO}_{2}$ in the upper ocean, J. Geophy. Res., 113, C04037, https://doi.org/10.1029/2007jc004416, 2008.

Tanhua, T., van Heuven, S., Key, R. M., Velo, A., Olsen, A., and Schirnick, C.: Quality control procedures and methods of the CARINA database, Earth Syst. Sci. Data, 2, 35-49, https://doi.org/10.5194/essd-2-35-2010, 2010.

Trudinger, C. M., Fraser, P. J., Etheridge, D. M., Sturges, W. T., Vollmer, M. K., Rigby, M., Martinerie, P., Mühle, J., Worton, D. R., Krummel, P. B., Steele, L. P., Miller, B. R., Laube, J., Mani, F. S., Rayner, P. J., Harth, C. M., Witrant, E., Blunier, T., Schwander, J., O'Doherty, S., and Battle, M.: Atmospheric abundance and global emissions of perfluorocarbons CF4, C2F6 and $\mathrm{C} 3 \mathrm{~F} 8$ since 1800 inferred from ice core, firn, air archive and in situ measurements, Atmos. Chem. Phys., 16, 11733-11754, https://doi.org/10.5194/acp-16-11733-2016, 2016.

Vollmer, M. K. and Weiss, R. F.: Simultaneous determination of sulfur hexafluoride and three chlorofluorocarbons in water and air, Mar. Chem., 78, 137-148, https://doi.org/10.1016/S03044203(02)00015-4, 2002.

Walker, S. J., Weiss, R. F., and Salameh, P. K.: Reconstructed histories of the annual mean atmospheric mole fractions for the halocarbons CFC-11 CFC-12, CFC-113, and carbon tetrachloride, J. Geophy. Res., 105, 14285-14296, https://doi.org/10.1029/1999jc900273, 2000.

Wallace, D. W. R. and Krysell, M.: Hydrolysis of Carbon Tetrachloride, Science, 246, 1638-1639, https://doi.org/10.1126/science.1638-a, 1989.

Warner, M. J. and Weiss, R. F.: Solubilities of chlorofluorocarbons 11 and 12 in water and seawater, Deep Sea Res. Pt. A, 32, 1485 1497, https://doi.org/10.1016/0198-0149(85)90099-8, 1985.

Waugh, D. W., Hall, T. M., and Haine, T. W.: Relationships among tracer ages, J. Geophys. Res.-Oceans, 108, 3138, https://doi.org/10.1029/2002JC001325, 2003.

Yvon-Lewis, S., Liu, Y., Hu, L., and O'Hern, J.: Selected CFC and HCFC Tracers Observed During the Gulf of Mexico East Coast Carbon (GOMECC) Cruise, AGU Fall Meeting Abstracts, San Francisco, OS53C-1321, 2008.

Yvon-Lewis, S. A. and Butler, J. H.: Effect of oceanic uptake on atmospheric lifetimes of selected trace gases, J. Geophy. Res.-Atmos., 107, 4414, https://doi.org/10.1029/2001JD001267, 2002. 